\title{
Mobile Communication Technology and National Identity in Sub-Saharan Africa
}

\author{
Donghyun Danny Choi, ${ }^{*}$ Benjamin Laughlin, ${ }^{* *}$ and Anna Schultz ${ }^{\dagger}$
}

June 2021

\begin{abstract}
We examine how the expansion of mobile internet infrastructure affects national identity in sub-Saharan Africa. In diverse societies where elections are contested along ethno-communal lines, we argue that access to mobile internet undermines national identity because it facilitates voter exposure to the polarizing tendencies of internet-based social media and communication platforms. Applying a difference-in-differences design on mobile coverage maps and geocoded survey data of more than 50,000 African citizens, we show that access to mobile internet reduces identification with the nation by up to 5-7 percentage points. To establish support for our electoral mechanism, we exploit as-if random variation in the timing of individuals' survey interviews relative to presidential elections, during which we argue divisive and polarizing forces are at their peak. Our analysis shows that electoral proximity intensifies the negative effect of mobile internet. These findings highlight how technological innovations can inhibit the process of state-building in diverse societies.
\end{abstract}

${ }^{*}$ Choi: Assistant Professor of Political Science, University of Pittsburgh, and Faculty Affiliate, Identity and Conflict Lab, University of Pennsylvania (email: dannychoi@pitt.edu); ${ }^{* *}$ Laughlin: Assistant Professor of Political Science, New York University Abu Dhabi (email: benjamin.laughlin@nyu.edu); ${ }^{\dagger}$ Schultz: Independent Scholar (email: schultz.anna@gmail.com). Corresponding Author: Donghyun Danny Choi (dannychoi@pitt.edu) 


\section{Introduction}

Innovations in communication technology have played a central role to the formation of national identities in the modern state. The widespread adoption of printing technology, for example, encouraged the use of a common written language, enabling communications between geographically dispersed groups that previously did not have the means necessary to interact with each other (Anderson, 1983). The process of engaging in common discourse and "imagining" themselves as a part of a broader community-one larger than their own ethno-communal groups-ultimately allowed citizens to develop a collective sense of belonging to their nation as a whole. The technology also provided political elites with a platform to promote an agenda establishing a common national history which would contribute to the formation of a national identity (Deutsch, 1966; Weber, 1976). ${ }^{1}$

Of the many advances in communications infrastructure since the invention of the printing press, mobile communications technology-mobile internet service in particular-has been arguably the most transformative. Unlike the dial-up and broadband internet, whose benefits have largely been confined to the developed world, the reach of cell phones has extended to a majority of populations in the developing world, including much of South and Southeast Asia, Latin America, and sub-Saharan Africa. The geographic extent of coverage is so broad that mobile internet is available in places where other types of infrastructural development have failed to penetrate. The parallels between the printing press and mobile internet-lowering the cost of communication, and connecting millions of previously unconnected people-may lead us to anticipate that the rapid expansion of cell phone networks over the past two decades would exert similar integrative pressures on users to develop attachments to their collective national communities.

Despite these clear parallels, there are strong reasons to be more skeptical of the integrative potential of mobile internet expansion, especially in the context of the developing world where such expansion is perhaps likely to be the most transformative. First, the structural, institutional, and so-

\footnotetext{
${ }^{1}$ While we focus on communication technology, other scholars focus on broader aspects of modernization as a whole. An earlier literature on state-building suggests that the process of modernization facilitates the construction of a national identity (Anderson, 1983; Gellner, 2008; Weber, 1976). A recent empirical investigation by Robinson (2014) has tested these theoretical arguments, and has found evidence consistent with the observation that modernization increases an individual's propensity to identify with the state.
} 
ciodemographic characteristics of the Global South today differ significantly from those of 18-19th century Western Europe, upon which much of the earlier literature linking technological innovations to the formation of a national identity have primarily focused (Gellner, 2008). Second, while its far-reaching nature might be similar to previous communications revolutions, distinctive features of mobile internet service, as a medium through which broad segments of the population gain lowcost access to internet-based infrastructure and modes of communication, may create conditions that foment polarization rather than integration (Lelkes, Sood and Iyengar, 2017; Settle, 2018).

These divergent theoretical expectations provide the motivation for our paper. In investigating the relationship between the expansion of mobile technology and national identity, we argue that in contexts where ascriptive (e.g., ethnic, racial, or religious) boundaries demarcate the axes of political competition, politicians are electorally motivated to promote a divisive agenda along these cleavages. Mobile phone coverage, and mobile internet in particular, spurs ethnic polarization and undermines identification with the nation by providing citizen access to internet-based social media platforms (such as Twitter or Facebook) increasingly used by politicians for campaigning, and facilitating communication via internet-based digital messaging platforms (such as Whatsapp) which, unlike traditional cellphone-based text messaging, allow for many-to-many interactions and serve as fertile ground for the spread of mis/disinformation. We further argue that these tendencies are amplified as the date of the election approach, when campaigning intensifies and the polarizing forces on these platforms are at their peak.

In providing support for this argument, we focus our attention on the case of sub-Saharan Africa. As shown in Figure 1, Africa has witnessed an explosive expansion in mobile internet service over the past decade, with the number of people who have access to mobile internet increasing from virtually zero in 2007 to 825 million in 2019. Mobile internet service now penetrates more than 79 percent of Africa's population. ${ }^{2}$ We combine detailed yearly geospatial data of mobile internet coverage and geocoded survey responses from rounds 3-7 of the Afrobarometer surveys, which

\footnotetext{
${ }^{2}$ For more information on the growth of mobile internet access see "New ITU data reveal growing Internet uptake but a widening digital gender divide," retrieved on November 26, 2020, at https : //www . itu . int/en/mediacentre/ Pages/2019-PR19. aspx. Figure A2 shows that the growth in mobile internet access has been accompanied by concordant increase in mobile internet subscriptions across Sub-Saharan Africa.
} 


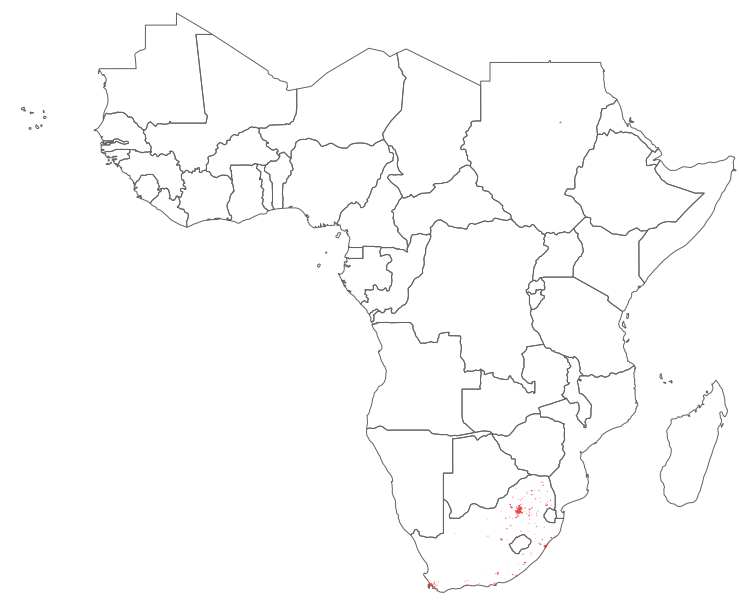

Mobile internet coverage in 2007

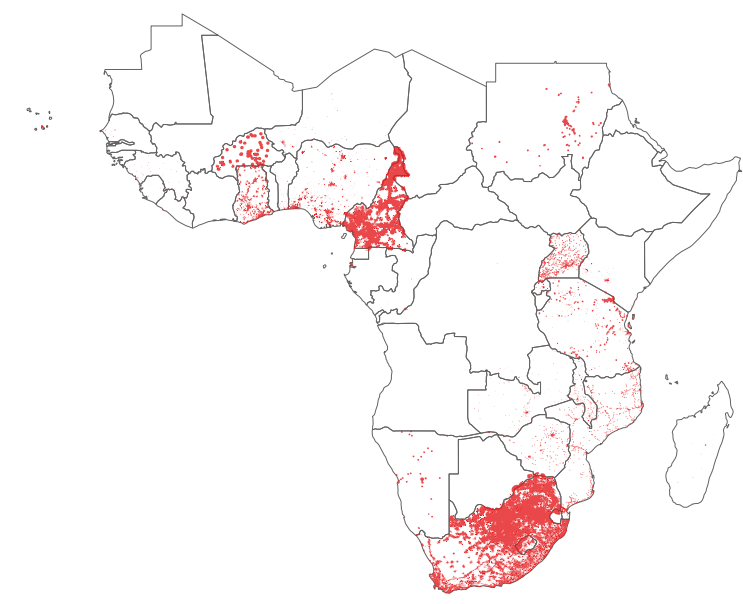

Mobile internet coverage in 2018

Figure 1: Maps illustrate the expansion of mobile internet coverage in sub-Saharan Africa between 2007 and 2018. Maps were created using coverage data provided by Collins Bartholomew and the GSM Association.

measure the extent to which an individual privileges their identification with their nation relative to the communal (ethnic, regional, religious) group to which they belong.

In order to identify the effect of mobile internet coverage on the extent to which citizens identify with the nation state, we implement a difference-in-differences (DiD) design, which exploits temporal variation in the extent of mobile internet coverage across different waves of the Afrobarometer. Using the DiD design, we find that expanded access to mobile internet service across Africa leads to a statistically significant decrease in an individual's propensity to identify with the nation over their ethnocommunal group by up to $5 \sim 7 \%$ points. These effects remain robust after accounting for demographic differences between individuals living with and without mobile coverage, as well as heterogeneity in local infrastructural and economic development that could potentially be correlated with service roll-out. By contrast, we do not detect any effect of the expansion of basic mobile phone service, which does not provide access to the internet-based social media and messaging platforms through which we argue election-driven polarization occurs.

To test our theoretical mechanism, we exploit as-if random variation in the timing of individual survey respondent's interview to the date of the presidential elections, during which polarizing 
forces are at their peak. If mobile internet functions as a key mechanism through which individuals are exposed to the polarizing influence of elections, we should expect people with mobile internet access to become less attached to the nation as high-salience elections draw nearer. We find that this is the case; proximity to elections amplifies the polarizing effects of mobile internet coverage.

Our findings offer insights regarding the sociopolitical consequences of one of the most significant developments in communications infrastructure in the world. While earlier work has tied the expansion of mobile phone service to group-level outcomes such as political violence, protest, and repression (Pierskalla and Hollenbach, 2013; Enikolopov, Makarin and Petrova, 2020; Christensen and Garfias, 2018), we show that it also has profound social-psychological implications for individuals in how the relate to their nation state. Given that the salience and persistence of ethnocommunal identities and the relative weakness of national identities have been identified as root causes of conflict and state fragility in Africa, our findings have important implications for the study of state-building in developing contexts.

Our research also contributes to the community of scholars working on deepening our understanding of identity-social, ethnic, national-as an outcome. Much of the work in this area has focused on how long-term processes or macrosocial structures such as colonial legacies and modernization affect ethnic or national identities (Bates, 1974; Posner, 2004; Robinson, 2014). Yet a recent group of scholars have examined the effect of meso-level factors that operate in the intermediate to short run on social identities (Peisakhin and Rozenas, 2018; Bleck and Michelitch, 2017). We join these scholars in arguing that a relatively recent development such as the expansion of mobile internet service can have consequences for how an individual defines their relationship to the state.

\section{Elections, mobile internet, and national identity}

In hypothesizing the relationship between mobile communication technology and national identity in diverse societies, we begin from an important observation in the existing literature in compar- 
ative and American politics; that electoral competition has the potential to reinforce pre-existing parochial divisions in society (Ferree, 2010; Michelitch, 2015). Scholars have characterized elections as a "zero-sum contest between groups, in which gains by any one group is considered as a loss for all others (Arriola, 2012, 11). Due to the widespread perception among voters that losing in elections means being excluded from power and the ability to access the distributive capabilities of the states, politicians are incentivized to mobilize and appeal to parochial interests in ways that sharpen communal antagonisms (Wilkinson, 2006). Others have also argued that elections constitute key junctures in which the relative standing of groups are subject to inherent uncertainty, and anxieties or concerns over the loss of status or recognition are intensified (Horowitz, 1985; Sambanis and Shayo, 2013). Since voters are motivated to stem these uncertainties and anxieties by expressively voting "for their group" (Brennan and Hamlin, 1998), politicians stand to benefit by utilizing campaign strategies that "evoke pride, grievances, or contempt" that are associated with parochial belongings (Gadjanova, 2017).

It is under these conditions-wherein elections tend to ossify voter attachment to their ethnocommunal identities, and politicians are incentivized to mobilize around them-that we argue that the expansion of mobile technology is likely to intensify polarization and undermine national identity. We specifically identify mobile internet technology as a channel of polarization, and focus on how it facilitates voter access to the polarizing potential of online social media platforms such as Twitter and Facebook, as well as messaging services such as Whatsapp, ${ }^{3}$ especially during periods of election campaigning.

Our intuition is motivated by the extant literature on the polarizing potential of internet-based social media in consolidated democracies of North America and Europe (Lelkes, Sood and Iyengar, 2017; Cinelli et al., 2021). ${ }^{4}$ Rather than serving as a forum for the cross-cutting exchange of ideas

\footnotetext{
${ }^{3}$ While these messaging services technically do not fall into traditional notions of social media, as Lupu, Bustamante and Zechmeister (2020) point out, it serves a similar purpose as Twitter and Facebook in that people join Whatsapp to i) share news and information and engage in discussion, ii) groups formed are quite large, often encompassing members outside of immediate family or friends, and iii) users often engage in communication with group members with whom they are not personally acquainted.

${ }^{4}$ We acknowledge that this perspective has recently been challenged by research in political science and economics. See Guess (2021) and Boxell, Gentzkow and Shapiro (2017) for examples of this work.
} 
and democratic dialogue, scholars have shown that these venues have become "echo chambers" in which individuals sort into clusters that share similar political opinions and attitudes, and thus seldom have the opportunity to interact with others that do not share in their beliefs (Colleoni, Rozza and Arvidsson, 2014; Settle, 2018). Furthermore, the extensive degree of self-sorting into homogeneous groups can exacerbate the well-documented tendency of individuals to selectively seek out information that reinforces their prior beliefs (Halberstam and Knight, 2016). Such exposure to like-minded individuals is associated with the adoption of more extremist positions that can lead to further polarization and radicalization (Mutz and Martin, 2001).

Furthermore, social media platforms provide fertile ground for the spread of mis/disinformation (Lazer et al., 2018; Allcott and Gentzkow, 2017). In an online environment where speech is unregulated and editorial forbearance on unchecked/unvalidated facts and stories-one of the corrective pressures that often exist in conventional print and broadcast news media-is absent, the likelihood that voters are exposed to misleading or incorrect information (otherwise referred to as fake news) on uncurated platforms such as Facebook or Twitter increases significantly. In providing corroborative evidence for this proposition, Guess, Nyhan and Reifler (2020) show that voters have been shown to be significantly more likely to visit websites with false-news rather than hard news immediately after accessing platforms such as Facebook. While some scholars have pointed out that active engagement with fake news (such as sharing) is restricted to a small subset of social media users (Guess, Nagler and Tucker, 2019; Grinberg et al., 2019), others have highlighted how the speed and breadth of fake news circulation significantly overshadows that of verified news (Vosoughi, Roy and Aral, 2018), suggesting that the reach of mis/disinformation on social media might extend far beyond the pool of individuals that actively and directly engage with such content.

The meteoric expansion of social media platforms and messaging service usage alongside the expansion of mobile internet in the Global South provide politicians with a new and potentially highly effective channel through which they can promote the parochial agenda described above 
(Ncube, 2019). ${ }^{56}$ Traditionally, politicians in the developing world have relied on conventional modes of campaigning such as handouts, door-to-door canvassing, or mass rallies to reach out to voters, which can become time and resource intensive (Brierley and Kramon, 2020). Facebook and Twitter, as well as messaging services such as Whatsapp provide politicians with many advantages over these modes of campaign outreach.

These platforms facilitate a broader dissemination of information regarding conventional campaign events, expanding the potential set of voters who are likely to attend. They can also allow the messages delivered in person by politicians at these campaign events to be spread far beyond the networks of voters who were physically present at the rally. But the opportunities afforded to politicians do not stop there; in addition to increasing the efficacy of conventional modes campaigning (Nyabola, 2018), social media and messaging platforms allow politicians to make direct contact with a significantly larger number of voters who would otherwise not be inclined to attend these in-person campaign events (Rajput, 2014; Adebanjo, 2019). Furthermore, with social media politicians are significantly less constrained in terms of the frequency with which they can reach out to their supporters, and in the extent of individual or group-level targeting or adjustment of their outreach to ensure that their message is having the intended impact (Nyabola, 2018). In addition, politicians obtain the ability to taint the image of their opponents relatively unhindered due to the unregulated nature of social media, and can expect to see their machinations percolate through the online sphere as their supporters disseminate and reproduce these negative attacks through their own social networks (Lupu, Bustamante and Zechmeister, 2020; Cheeseman et al., 2020). Where political friends and foes are primarily defined along ascriptive group boundaries, these dynamics are likely to intensify animus towards both candidates and voters belonging to outgroups and

\footnotetext{
${ }^{5}$ According to website Internet World Stats (https://www. internetworldstats.com/) Africa has an overall internet penetration rate of $46.2 \%$. The continent is estimated to have a total of 264 million Facebook subscribers, with a penetration rate of $19.3 \%$. This average rate masks significant variation across countries, with countries such as South Africa, Namibia reporting significantly higher rates of 30 40 percent.

${ }^{6}$ While similar data for messaging services such as Whatsapp are not readily available, journalistic accounts suggest that the total number of Whatsapp users far outnumber Facebook or Twitter users, with many reporting that a large majority of internet data is consumed on Whatsapp. See Culture Trip, "Why Most of Africa's Data is Used on WhatsApp," retrieved June 1, 2021. https://theculturetrip.com/africa/articles/ why-most-of-africas-data-is-used-on-whatsapp/.
} 
strengthen loyalty to their own group.

Access to the mobile internet places voters directly under the influence of the polarizing social media environment cultivated by these politicians. The frequent interaction with polarizing information and content is likely to set in motion the process for voters to reify their loyalties to their ethnic groups and disassociate themselves from a "national community" that their reified group loyalties undermines. But it is not just through the influence of the divisive rhetoric that politicians advance on internet-based platforms that leads voters down the path of polarization (Mpofu, 2019). As suggested earlier, voters themselves can engage in a class of well-documented behaviors that perpetuate or even intensify these processes of polarization; such as confining their interactions online to individuals or groups who share their parochial alignments, or selectively consuming and sharing information that reinforces rather than contradicts their own beliefs.

The preceding discussions have highlighted the importance of mobile internet technology in shaping identities in diverse societies. We generate the following testable, empirical predictions regarding the impact of mobile internet service expansion. ${ }^{7}$

Hypothesis 1 (Mobile internet coverage): The expansion of mobile internet service in particular, is likely to increase citizen identification with parochial ethnocommunal identities, and therefore decrease national identification.

We have also emphasized how periods of electoral campaigning are likely to be moments where the polarizing forces are at their peak. We thus anticipate that as election campaigns intensify along the election cycle-i.e. as the day of the election approaches-voters with access to mobile internet service will be even more inclined to identify with their ethnocommunal groups, and less with their national community.

\footnotetext{
${ }^{7}$ We note, however, that our posited mechanisms for mobile internet fails to extend to the case of basic mobile phone service - which provides users with "talk and text" capabilities-because it does not grant politicians or voters with access to the internet and the social media platforms that are based on internet technology nor internet-based messaging apps such as Whatsapp or Telegram.
} 
Hypothesis 2 (Mobile internet $\times$ election proximity): The polarizing influence of mobile internet is likely to intensify as elections draw near, during which polarizing forces are their peak.

We end this theoretical discussion with an important caveat; we do not make any predictions regarding general equilibrium impacts of mobile internet access writ large, nor adjudicate whether it constitutes a net positive or negative for social, economic, or political life in Africa. Empirical research that examines the economic consequences of mobile coverage have found that it generally has a positive impact in improving generalized welfare (Aker, 2008; Aker and Mbiti, 2010), eliminating inefficiencies in commodity prices in different markets (Muto and Yamano, 2009), as well as in reducing poverty (Suri and Jack, 2016). However, other important work has reported an increase in political violence, suggesting that the net impact of mobile technologies might be unclear (Pierskalla and Hollenbach, 2013). We therefore direct our efforts on empirically validating our posited link between mobile internet expansion, polarization, and national identity.

\section{Context: Mobile Technology and Identity Politics in Africa}

We study the implications of mobile internet access on elections and identity politics in a period of an unprecedented expansion of mobile communications infrastructure across the African continent. Figure A2 in the SI Appendix shows that within a span of just over a decade, the continent went from virtually no mobile internet penetration to close to $80 \%$ of the population ( 825 million) covered by 3G mobile service-the minimum threshold service for consistent access to internet via mobile phones-and more than $30 \%$ with access to a rapidly expanding higher-speed infrastructure such as $4 \mathrm{G}$ and $5 \mathrm{G}$ service.

The expansion of mobile internet service has been accompanied by a surge in active social media users (numbering more than 260 million Facebook users and a much higher penetration for Whatsapp), with an overwhelming majority (93\%) reporting that they primarily access social me- 
dia platforms such as Facebook or Twitter via their mobile phones. ${ }^{89}$ More important than the sheer number of new social media users is the manner in which social media platforms are used by those with access: there is significant reason to believe that mobile internet and social media are fast becoming fora for citizens to acquire and share information regarding politics and government.

Figure 2 presents data from 2017 Pew Global Attitudes Surveys across six Sub-Saharan African countries regarding patterns of internet and social media usage across a representative sample of adults (Pew Research Center, 2018). The top panel of Figure 2 plots the proportion of individuals who report that they use the internet for either economic or political purposes. In step with the much-discussed emergence of online mobile money solutions, slightly less than $50 \%$ of respondents across the six African countries report using the internet to make or receive payments. But more surprisingly, an even higher proportion of internet users report that they use the internet to obtain information about politics and government services. We observe similar patterns in responses to the question probing the reasons internet users post on social media platforms. As seen in the bottom panel of Figure 2, while social media users more commonly report posting to share views about sports, close to $40 \%$ of all users report using social media platforms to share their political views. ${ }^{10}$

The emergence of mobile internet and social media as a center of political activity is likely related to why political parties and politicians are increasingly establishing a social media presence and taking their election campaigns to these platforms. Yet as politicians turn their eyes towards social media, concerns over the potentially divisive and polarizing potential of such activities have already begun to accumulate. The 2017 presidential elections in Kenya provide a clear example of how online social media platforms can foment extreme polarization and cross-ethnic tensions and hostility.

\footnotetext{
${ }^{8}$ See Baobab News, "Digital 2019: Global and African Social Media use Accelerates”, retrieved at https : //africa . baobab.news/2019/07/03/digital-2019-global-and-african-social-media-use-accelerates/ on November 24, 2020

${ }^{9}$ The yearly growth rate in the number of social media platform users has outpaced the growth of mobile internet infrastructure itself between 2018 and 2019. Between 2018 and 2019 alone, an additional 25-30 million individuals newly registered as mobile social media users (13-17\% increase), in comparison only an $8 \%$ increase in mobile internet users.

${ }^{10}$ The Pew Global Surveys, conducted in 2017 also tracked the proportion of individuals who report that they have posted their own thoughts on political or social issues online. Respondents in African countries such as South Africa $(11 \%)$, Kenya (14\%), and Nigeria (17\%) are significantly more likely than citizens in countries in Europe, such as Greece $(6 \%)$, Hungary (5\%), Poland (7\%) to report that they have done so in the past year.
} 


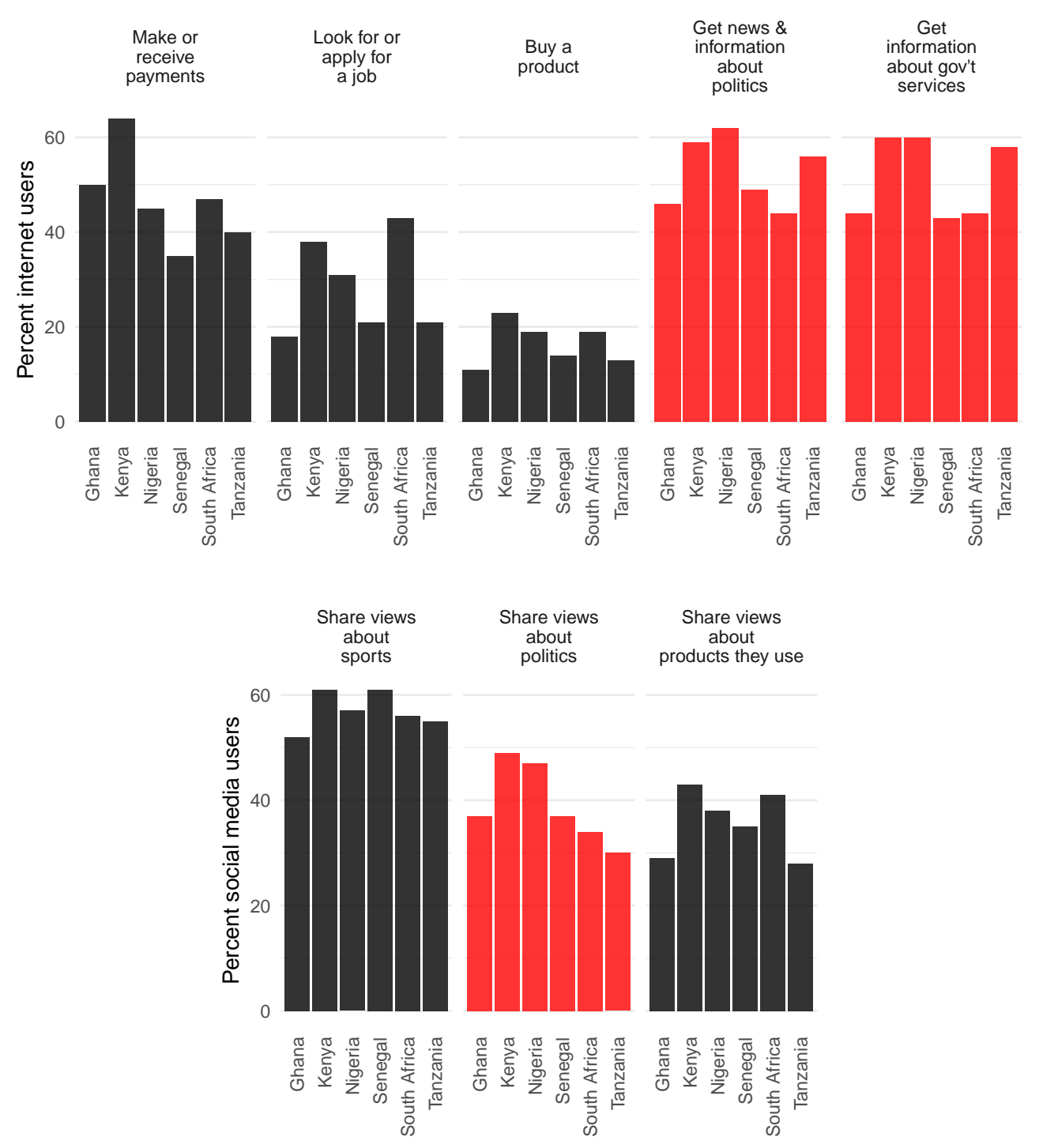

Figure 2: Africans use the internet to get news about politics and to post to social media their political views. Data source: Pew Global Attitudes Survey, Spring 2017.

As the competition between incumbent president Uhuru Kenyatta and opposition coalition leader Raila Odinga escalated in the run-up to the elections, social media platforms were inundated with negative posts—often by politicians communicating in their ethnic group's vernacular-designed to generate anxieties about the consequences of electoral defeat in the hands of ethnic others. ${ }^{11}$

Similar concerns over the use of social media as a forum for instigating interethnic tensions were

\footnotetext{
${ }^{11}$ Voice of America, "In Volatile Kenya, MP and Former Senator Detained Over Hate Speech Allegations", https : // www.voanews.com/africa/volatile-kenya-mp-and-former-senator-detained-over-hate-speech-allegations on November 24, 2020
} 
also raised during the 2019 Presidential elections in Nigeria. As the informal system of rotational presidency between the predominantly Muslim / Hausa-Fulani dominated north and Christian / Yoruba-Igbo dominated south collapsed in 2015, political candidates at both the national and local levels have used the rhetoric of inter-ethnic intolerance for the purpose of negative mobilization (Ezeibe, 2020). Rumors attempting to dehumanize opponents and stoke fear of imminent terrorism and violence were spread by the incumbent APC and the opposition PDP and rapidly diffused throughout social media. The misinformation and hate speech circulated predominantly through social media platforms such as Twitter and Facebook during this period of intense electioneering was of such grave concern that the APC-controlled Nigerian Senate quickly drafted a draconian piece of legislation that levies severe punishment (death or life sentence) for those found guilty of engaging in hate speech. ${ }^{12}$

\section{Data and research design}

\subsection{Geocoded public opinion data}

To estimate the effect of new technology on national identification, we combine geocoded individual survey responses with data on the geographic extent of mobile internet coverage. We overlay these coverage maps with geocoded individual-level data from rounds 3-7 of the Afrobarometer Surveys, conducted between 2005 and 2018. We note that rounds 1 6 of the Afrobarometer surveys were geocoded retroactively, to varying levels of precision. In order avoid the risk of misclassifying individuals that fall within or outside of mobile coverage boundaries, we include only those respondents coded at the highest two levels of precision-those coded precisely to a specific location (precision code 1 ), and those that are coded within $25 \mathrm{~km}$ of the exact location (precision code 2 ). As seen in Figure 3, the combined data include individuals from 27 sub-Saharan African countries.

Our main dependent variable is derived from responses to the Afrobarometer question:

\footnotetext{
${ }^{12}$ Deutsche Welle, "Nigeria bill aims at punishing hate speech with death', retrieved at https : / /www.dw.com/en/ nigeria-bill-aims-at-punishing-hate-speech-with-death/a-51419750 on November 24, 2020
} 


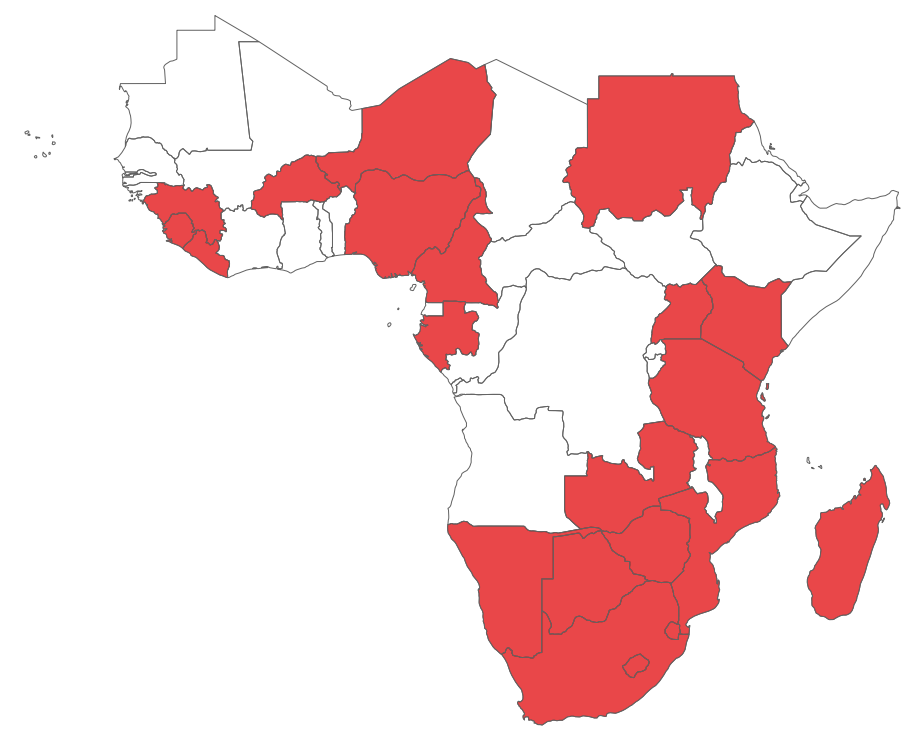

Figure 3: Countries included in the main analysis presented in the paper. To be included, a country needed to be in at least two Afrobarometer surveys for which mobile internet coverage data was available from the GSMA.

"Let us suppose that you had to choose between being a [respondent's national ID] and being a [respondent's ethnic group]. Which of the following best expresses your feelings?"

Responses range from 1 ("I feel only [ethnic]") to 5 ("I feel only [national]"). With this measure, the strength of national and ethnic identities are defined relative to one another. For our purposes, this is useful: we conceive of ethnic and national identities to be competing to some extent. ${ }^{13}$ One implication, however, is that movement from, for example, "I feel more [national] than [ethnic]" to "I feel equally [national] and [ethnic]" could represent a reduction in national identification, an increase in ethnic identification, or both. Figure 4 shows the distribution of responses among geolocated respondents in Afrobarometer rounds 3 7 in our difference-in-difference setup. Our preferred outcome variable is an indicator for whether the respondent identifies more nationally than ethnically, which accounts for $49 \%$ of the sample.

\footnotetext{
${ }^{13}$ Robinson (2014) has elaborated on the benefits of employing this relative measure of national identity; first, a question item probing absolute levels of national and ethnic identification separately would require us to assume that respondents map intensity of identification onto the scale in similar ways. Second, the relative juxtaposition of national versus ethnic identities are in line with the constructivist notion of identities that individuals hold identifications with multiple identity groups and that relative salience of one identity vis-à-vis another is more important and meaningful than the strength of attachment to a single identity by itself.
} 


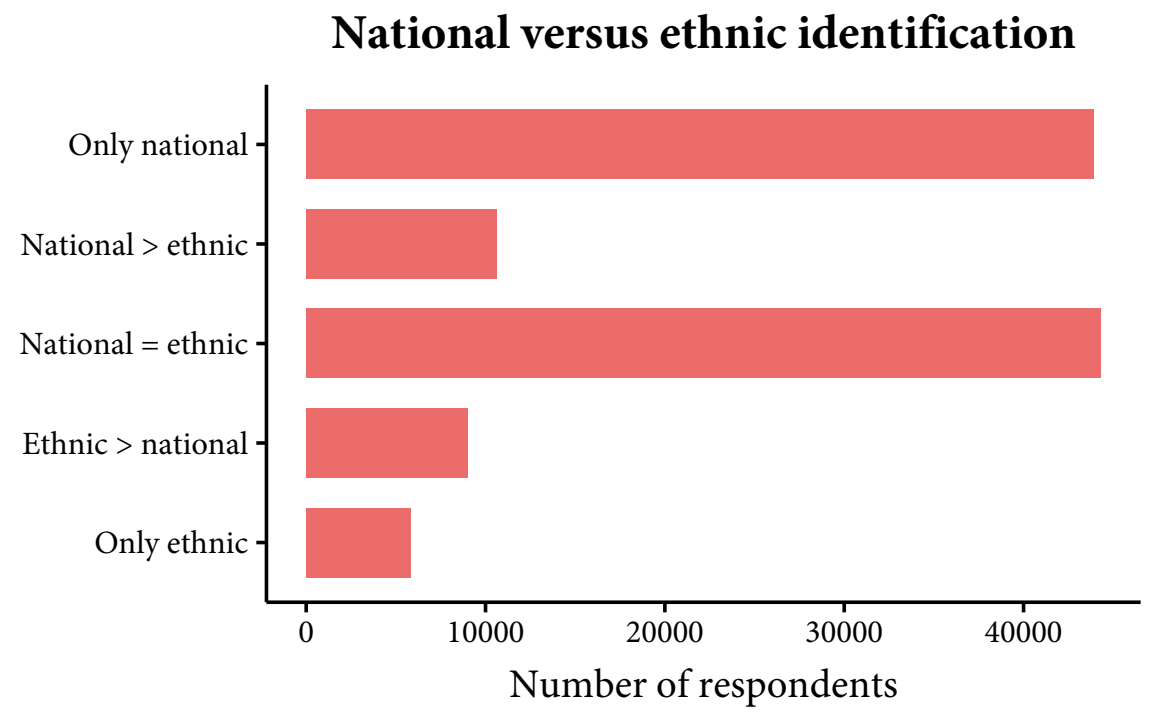

Figure 4: The distribution of national versus ethnic identification in Afrobarometer rounds 3-7. For our main outcome, we use an indicator for whether the respondent identifies more nationally than ethnically.

\subsection{Mobile service coverage data}

Data on the spatial extent of mobile phone coverage is provided by Collins Bartholomew and the GSM Association, which compile coverage data from network providers. These annual maps show the geographic extent of $2 \mathrm{G}$ and $3 \mathrm{G}$ cell phone coverage, representing the ability to make phone calls and send text messages $(2 \mathrm{G})$, or more comprehensive access to the internet or social media platforms and online messaging apps via mobile internet connections (3G). For our analysis, we choose the year of coverage data on a country-by-country basis, selecting the most recent coverage data collected prior to the beginning of that country's survey. In most cases the most recent coverage information is reported less than a year prior to the survey launch. Combining survey responses with mobile coverage spatial polygons allows us to locate whether respondents fall within or outside of mobile coverage boundaries. We prefer this fine-grained geographic data over other measures because it offers information on the availability of mobile internet over the longest possible time period and lacks the confounding intrinsic to an individuals decision to use the internet. However, we validate this measure using self-reported mobile phone and internet use, where available, and find a strong correspondence, as shown in section A.4 in the SI appendix. 


\subsection{Difference-in-differences strategy}

To analyze the effect of mobile internet coverage on national identity, we employ a difference-indifferences design using the following specification:

$$
y_{i j t}=\alpha+\beta \text { Covered }_{i j t}+\gamma \text { EverCovered }_{i}+\delta_{j}+\zeta_{t}+\theta X_{i t}+\varepsilon_{i j t}
$$

where $y_{i j t}$ is an outcome for individual $i$ in geographic area $j$ in time period $t$, Covered $_{i j t}$ is an indicator variable for whether the individual has mobile internet coverage at time $t$, and EverCovered ${ }_{i}$ is an indicator for whether individual $i$ is in the treatment group-whether $i$ 's location receives mobile internet during the period of our study. $X_{i t}$ represents a vector of individual covariates. Geographic area (country or district) fixed effects are represented by $\delta_{j}$ and $\zeta_{t}$ represents survey round fixed effects. We cluster standard errors by locality-the level at which mobile coverage is assigned. To correct for spatial autocorrelation we also calculate Conley (1999) standard errors that account for spatial correlation between localities that fall within 500 kilometers of each other.

As an alternate specification we aggregate the treatment to $0.5 \times 0.5$ degree grid cells: approximately $55 \times 55 \mathrm{~km}$. This allows us to a estimate a standard DiD model with survey-round and grid cell fixed effects. Grid cell fixed effects hold constant any characteristics that vary between these geographic units, avoiding the potential for bias induced by systematic differences between areas that get mobile internet coverage earlier or later, which may not be fully captured by the treatment group indicator in equation 1 or control variables. In this specification, individuals are coded as treated if the majority of respondents in the grid cell during a survey wave have mobile internet coverage. Because treatment is at the level of the grid cell, we cluster standard errors by grid cell.

To test whether election proximity plays in moderating the effect of mobile internet, we employ an identification strategy developed by Eifert, Miguel and Posner (2010). Eifert et al. exploited the fact that the dates on which individual interviews for the Afrobarometer surveys were implemented are determined orthogonally to the dates of the elections, which are chosen by statutory provisions 
in each country. ${ }^{14}$ We therefore the calculate the number of months between the date of a respondent's interview and the closest presidential election in the respondent's country. We then create an interaction term between the "months to election" measure and our treatment indicator for mobile internet coverage.

\section{Main Findings}

\subsection{The effect of mobile internet on national identity}

Table 1 reports the effect of mobile internet coverage on national identification using the DiD specification shown in equation 1 with robust standard errors clustered at the locality level in parentheses and Conley (1999) standard errors that adjust for spatial autocorrelation presented in brackets. Column (1) reports results of a baseline specification without additional covariates, but with country fixed effects that allow us to tighten our inferences to within country variation in over-time mobile internet coverage expansion. In line with our expectations, this baseline specification shows that gaining access to mobile internet coverage decreases an individual's propensity to identify with the nation (over their ethnic group) by around 6\% points. Column (2) presents specifications with individual-level demographic controls for gender, age, completion of secondary education, and whether the respondent's residence is classified as urban or rural by the Afrobarometer surveys added to the baseline specification. The inclusion of these individual-level covariates does little to change the substantive negative effect of mobile internet coverage. ${ }^{15}$

While the robustness of the findings to the addition of these pretreatment demographic controls should assuage some inferential concerns, we further present specifications that restricts our inferences to smaller geographic units, based on the intuition that country fixed effects may be insufficient to fully absorb geographic heterogeneity. Columns (3) (4) employ district fixed effects in lieu of country fixed effects. ${ }^{16}$ While the size of the coefficient decreases marginally from $6.6 \%$

\footnotetext{
${ }^{14}$ We display balance in election proximity across key variables in Table ??.

${ }^{15}$ Analyses using the five-point identity scale as the outcome variable, for this and subsequent tables, is presented in Section A.2 in the SI appendix. The results are substantively similar.

${ }^{16}$ To create district-level dummies, we use the district (admin level 1) boundaries from the 2008 Global Administra-
} 
Table 1: Effect of mobile internet coverage on national identity

\begin{tabular}{lcccccc}
\hline \hline & \multicolumn{5}{c}{ Dependent variable: } \\
\cline { 2 - 7 } & \multicolumn{5}{c}{ Identify More Nationally Than Ethnically (Binary) } \\
& $(1)$ & $(2)$ & $(3)$ & $(4)$ & $(5)$ & $(6)$ \\
\hline Mobile internet & -0.061 & -0.066 & -0.056 & -0.057 & -0.062 & -0.063 \\
& $(0.011)^{* * *}$ & $(0.011)^{* * *}$ & $(0.010)^{* * *}$ & $(0.010)^{* * *}$ & $(0.019)^{* * *}$ & $(0.019)^{* * *}$ \\
& {$[0.021]^{* *}$} & {$[0.022]^{* *}$} & {$[0.016]^{* * *}$} & {$[0.017]^{* * *}$} & {$[0.020]^{* *}$} & {$[0.020]^{* *}$} \\
\hline Fixed effects & Country & Country & District & District & Grid cell & Grid cell \\
Demographic controls & No & Yes & No & Yes & No & Yes \\
Observations & 55,238 & 54,809 & 55,238 & 54,809 & 55,238 & 54,809 \\
\hline \hline
\end{tabular}

Notes: DiD results show the effect of mobile internet on national identification. All specifications include fixed effects for survey wave and either country, district, or grid cell. Columns 5 and 6 aggregate the treatment to $0.5 \times 0.5$ degree grid cells to enable two way fixed effects. Demographic controls include individual-level measures of gender, age, completion of secondary education, and whether their residence is classified as urban or rural by Afrobarometer. Robust standard errors clustered at the locality or grid cell level are shown in parentheses. To correct for spatial autocorrelation of up to $500 \mathrm{~km}$, Conley (1999) standard errors are shown in brackets. ${ }^{*} \mathrm{p}<0.05 ;{ }^{* *} \mathrm{p}<0.01 ;{ }^{* * *} \mathrm{p}<0.001$.

points to $5.7 \%$ points, the mobile internet effects remain still strongly negative and significant at $\mathrm{p}<0.001$. In addition, columns (5) (6) present specifications that aggregate the treatment to the $0.5 \times 0.5$ degree grid cell. The coefficients on mobile internet coverage do not change substantively. Combined, we believe these results provide broad evidence in support of our argument that access to mobile internet coverage will increase polarization across existing parochial identities and prevent the emergence of a collective national identity. ${ }^{17} 18$

\subsection{Design validation}

The difference-in-differences design relies on the assumption of parallel trends-that national identification in treated and untreated areas would have followed similar patterns absent treatment.

tive Unit Layers spatial database, created by the Food and Agriculture Organization (FAO) of the United Nations. Use of 2008 boundaries for all our analyses ensures that the boundaries are pre-treatment and do not change over time.

${ }^{17}$ Alternate outcomes that can be used to demonstrate the polarizing effects of mobile internet are extremely limited in the Afrobarometer surveys. However, we present some evidence on an outcome-perceptions that the respondent's group is treated unfairly-which is available consistently through rounds 3-7 in SI Appendix Table A10. In line with our negative effect on national identification, we find that mobile internet increases perceptions of unfair treatment among respondents by around $2 \sim 3 \%$ points.

${ }^{18}$ The results in Table 1 hold when we include linear time trends in the specification. They are omitted due to space constraints but available upon request. 
Though this assumption is untestable, its plausibility is often assessed using pre-treatment trends. Differential trends between treatment and control groups prior to actual changes in coverage would suggest that differential trends during the treatment period could be driven by other factors. We test whether differences in national identity precede changes in mobile coverage by estimating equation 1 with the addition of one and two period leads to the treatment variable. That is, we include respondent's treatment status for the survey waves that occur after after the actual interview. Results

are shown in SI Appendix Table A8. In all specifications the effect of mobile internet coverage on national identity remains negative and statistically significant at conventional levels. Coefficients for the leads of mobile internet coverage, on the other hand, representing the effect of future mobile internet coverage on national identity, have point estimates near zero and are not significant at conventional levels. This adds confidence that our $\mathrm{DiD}$ approach will recover valid estimates of the effect of mobile internet coverage.

\subsection{Mechanism: Elections and the intensification of polarization}

Does proximity to elections moderate the effect of mobile internet coverage on national identity? Our theoretical discussions highlighted the possibility that the polarizing nature of elections in Africa would intensify the negative effect of mobile internet coverage. In Table 2 and Figure 5, we put these ideas to the test in the DiD framework. We estimate the same models from Table 1, but with an interaction term between the mobile internet coverage variable and the number of months between the date of the survey interview and the nearest presidential election in the respondent's country.

Table 2 reports findings from these analyses. In line with our expectations, the effect of mobile internet service expansion is strongly moderated by the temporal distance to elections. Across different specifications reported in columns (1) (6), the interaction term remains positive and consistent, and is statistically distinguishable from zero at $\mathrm{p}<0.01$. Substantively speaking, the magnitude of the coefficient means that an additional month closer to the election will decrease (since the months to election variable decreases as the election approaches) the proportion of individuals 
Table 2: Heterogeneity of the effect of mobile internet coverage by election proximity

\begin{tabular}{lcccccc}
\hline \hline & \multicolumn{5}{c}{ Dependent variable: } \\
\cline { 2 - 7 } & \multicolumn{7}{c}{ Identify More Nationally Than Ethnically (Binary) } \\
& $(1)$ & $(2)$ & $(3)$ & $(4)$ & $(5)$ & $(6)$ \\
\hline Mobile internet & -0.127 & -0.130 & -0.128 & -0.128 & -0.142 & -0.145 \\
& $(0.016)^{* * *}$ & $(0.016)^{* * *}$ & $(0.015)^{* * *}$ & $(0.015)^{* * *}$ & $(0.029)^{* * *}$ & $(0.029)^{* * *}$ \\
& {$[0.036]^{* * *}$} & {$[0.036]^{* * *}$} & {$[0.033]^{* * *}$} & {$[0.033]^{* * *}$} & {$[0.038]^{* * *}$} & {$[0.037]^{* * *}$} \\
Months from election & -0.003 & -0.003 & -0.003 & -0.003 & -0.003 & -0.003 \\
& $(0.0005)^{* * *}$ & $(0.0005)^{* * *}$ & $(0.0004)^{* * *}$ & $(0.0004)^{* * *}$ & $(0.001)^{* * *}$ & $(0.001)^{* * *}$ \\
Mobile internet $\times$ & {$[0.001]^{* *}$} & {$[0.001]^{* *}$} & {$[0.001]^{* *}$} & {$[0.001]^{* * *}$} & {$[0.001]^{* *}$} & {$[0.001]^{* *}$} \\
Months from election & 0.004 & 0.004 & 0.004 & 0.004 & 0.005 & 0.005 \\
& $(0.001)^{* * *}$ & $(0.001)^{* * *}$ & $(0.001)^{* * *}$ & $(0.001)^{* * *}$ & $(0.002)^{* *}$ & $(0.002)^{* *}$ \\
& {$[0.002]^{*}$} & {$[0.002]^{*}$} & {$[0.002]^{* *}$} & {$[0.002]^{*}$} & {$[0.002]^{*}$} & {$[0.002]^{*}$} \\
\hline Fixed effects & Country & Country & District & District & Grid cell & Grid cell \\
Demographic controls & No & Yes & No & Yes & No & Yes \\
Observations & 55,238 & 54,809 & 55,238 & 54,809 & 55,238 & 54,809 \\
\hline \hline
\end{tabular}

Notes: DiD estimates of the heterogeneous effects of access to mobile internet on national identity by proximity to elections are shown. Robust standard errors clustered at the locality or grid cell level are shown in parentheses. To correct for spatial autocorrelation Conley (1999) standard errors are shown in brackets. ${ }^{*} \mathrm{p}<0.05$; ${ }^{* *} \mathrm{p}<0.01{ }^{* * *} \mathrm{p}<0.001$.

identifying with the nation by around $0.4 \sim 0.5 \%$ points more in comparison to those without mobile internet coverage. ${ }^{19}$

The line graph in Figure 5 plots the effect of mobile internet coverage on national identification by time to the closest election. Results are shown for column (4) in Table 2. For respondents surveyed far from elections, we observe no relationship between mobile internet access and national identification. However, the effect of mobile internet strengthens with election proximity and becomes statistically significant. For respondents within 10 months of an election (31.8\% of the sample), access to mobile internet decreased national identity by over $9 \%$ points. ${ }^{20}$ This finding aligns with our theoretical argument that access to the polarizing influences of the internet during electoral campaigns, facilitated by mobile internet coverage, drives the negative effect of mobile technology on national identity.

\footnotetext{
${ }^{19}$ We report the analysis in Table 2 with the full set of controls included in Table 3 in SI Appendix Table A6. The inclusion of this extensive set of controls do not substantively alter the results.

${ }^{20}$ Figure A10 in the SI Appendix shows the distribution of the "months to election" variable.
} 


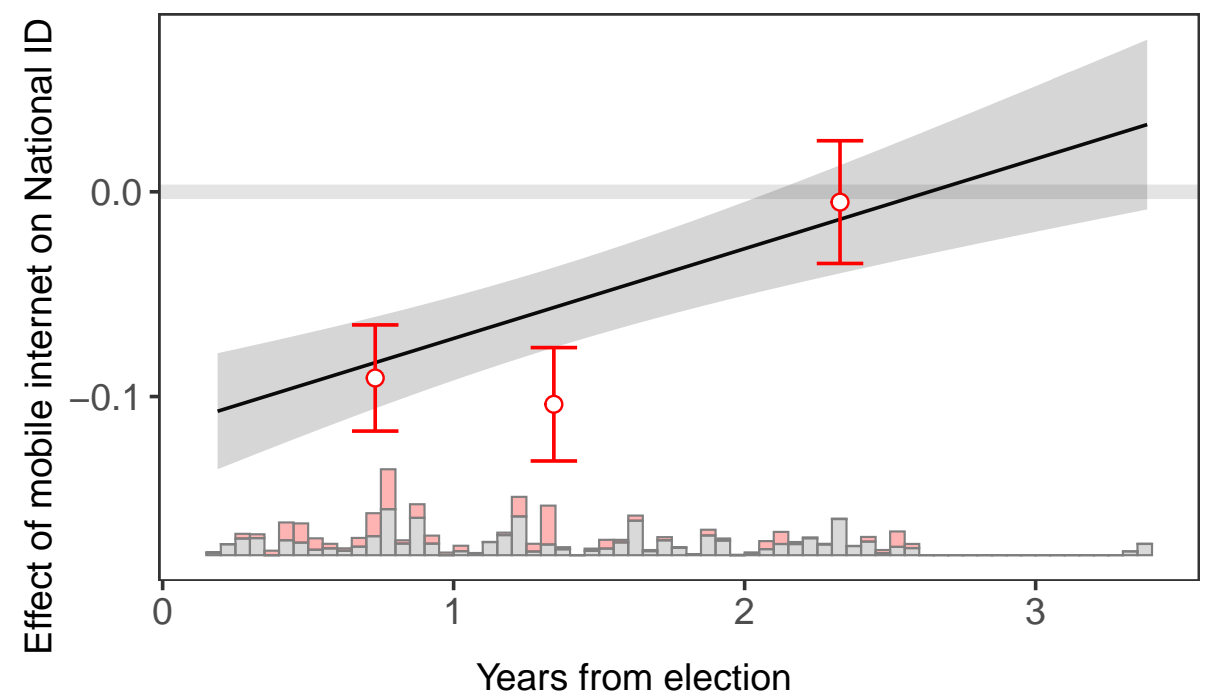

Figure 5: Heterogeneous effects of mobile internet on national identity by election proximity, with respondents in three bins: those surveyed less than 1 year from the election, between 1 and 2 years from the election, and 2 or more years from the election. 95 percent confidence intervals clustered by locality are shown.

While we expect polarizing rhetoric accessed over mobile internet to be more prevalent near elections, it is possible that this rhetoric does not increase linearly with proximity to elections. To address the possibility of non-linearity, we divide the time-to-elections variable into three categorical distance bins (as recommended by Hainmueller, Mummolo and $\mathrm{Xu}$ (2019)) that allow for a more flexible functional form. Figure 5 displays the results with time-to-election bins of up to one year, 1-2 years, and 2+ years. The effect of mobile internet $2+$ years from an election is indistinguishable from zero. Closer to the election, mobile internet coverage substantially lowers national identification.

\subsection{Alternative Explanations}

We have argued that mobile internet decreases attachment to national identities through an electoral mechanism. However, we might be concerned that the mechanism underlying our effect operates through mechanisms other than the electoral one we propose in the preceding sections. We therefore present a set of tests that probes this possibility more closely. 
First, access to mobile internet may have increased individual respondents' wealth, which may be moderating the effects of mobile internet coverage on identity. Access to mobile networks could increase individual or household income by lowering barriers to accessing information on prices and job or business opportunities. If wealth also induces changes in identity, the wealth effects of mobile internet access might explain our results. SI Appendix Table A5 includes a measure individual wealth derived from asset ownership consisting of an additive index of indicators of whether a survey respondent's household owns a radio, a television, and a motor vehicle. The effect of mobile internet when controlling for household wealth are a similar magnitude to estimates from Table $1 .{ }^{21}$ 22

Second, there is the possibility that these results are driven by selective expansion of mobile internet coverage into affluent areas. Mobile internet antennas have a shorter range than does basic $2 \mathrm{G}$ mobile service, and profit motivated mobile network providers are most likely to first provide mobile internet coverage in wealthy urban areas. Cell towers require electricity and road access for maintenance, so individuals far from roads or electrical transmission lines are less likely to have mobile internet coverage. We probe this possibility in Table 3, columns (1) (6). In specifications (1) (3), we first control for a time-varying subnational measure of population density. In columns (4) (6), we also include covariates measuring the geographic distance between a respondent's home and both the road network and the electrical transmission grid. We constructed these measures by calculating the geodesic distance between every respondent and the closest points on the road network and electricity grids. ${ }^{23}$ Inclusion of these covariates does not substantially change the point estimates or statistical significance of mobile internet coverage.

Third, mobile internet coverage may simply accompany a broader modernization process. A number of scholars of African politics have identified development as a source of increased ethnic competition and polarization (Bates, 1974; Posner, 2004). This could lead to a spurious finding, where ethnic polarization is the result of economic development, not mobile internet coverage. We

\footnotetext{
${ }^{21}$ It is important to note that wealth is potentially affected by mobile internet coverage (i.e. post-treatment), and the results should be interpreted with caution.

${ }^{22}$ We also report models with controls for traditional news media consumption (TV, radio, newspapers) in Table A5.

${ }^{23}$ Details of how these variables variables were constructed can be found in the "Notes" section of Table 3.
} 


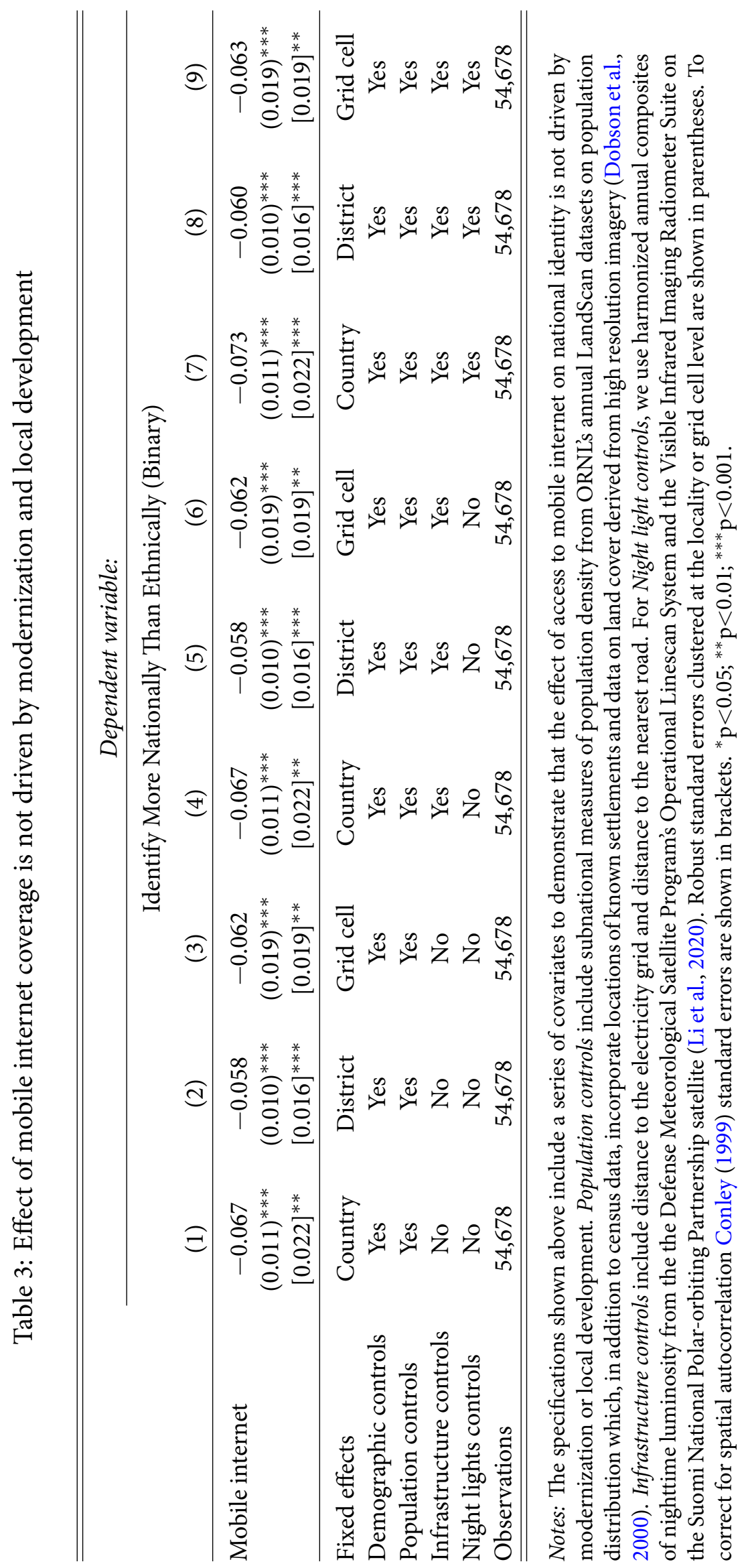


test these alternative theoretical explanations in Table 3, columns (7) $(9)$. We add time-varying controls for nighttime lights intensity, a broadly used measure of local economy activity. If economic development is the reason for the effect of mobile internet on identity, we would expect the effect of mobile internet coverage to disappear-or at least be reduced — when controlling for nighttime lights. Instead, the estimated effect of mobile internet on national identity does not change substantively, suggesting that modernization per se does not fully account for our results. ${ }^{24}$

\section{Placebo Tests Using Basic Mobile Coverage}

Table 4: Placebo test: effect of access to basic mobile phone service (2G) on national identification

\begin{tabular}{lcccccc}
\hline \hline & \multicolumn{7}{c}{ Dependent variable: } \\
\cline { 2 - 7 } & $(1)$ & $(2)$ & $(3)$ & $(4)$ & $(5)$ & $(6)$ \\
\hline Basic mobile coverage & 0.010 & 0.004 & 0.013 & 0.009 & 0.014 & 0.014 \\
& $(0.014)$ & $(0.014)$ & $(0.013)$ & $(0.013)$ & $(0.025)$ & $(0.025)$ \\
& {$[0.020]$} & {$[0.020]$} & {$[0.019]$} & {$[0.018]$} & {$[0.026]$} & {$[0.026]$} \\
\hline Fixed effects & Country & Country & District & District & Grid cell & Grid cell \\
Demographic controls & No & Yes & No & Yes & No & Yes \\
Observations & 39,247 & 38,717 & 39,247 & 38,717 & 39,247 & 38,717 \\
\hline \hline
\end{tabular}

Notes: Results of a placebo test using access to basic mobile phone service (2G), which does not provide access to the internet-based platforms through which we argue election-driven polarization occurs. The sample is restricted to the country-waves prior to the intoduction of mobile internet in each country. Robust standard errors clustered at the locality or grid cell level are shown in parentheses. To correct for spatial autocorrelation Conley (1999) standard errors are shown in brackets. ${ }^{*} \mathrm{p}<0.05 ;{ }^{* *} \mathrm{p}<0.01 ;{ }^{* * *} \mathrm{p}<0.001$.

Our posited mechanisms for mobile internet do not extend to basic mobile phone service, which provides users with "talk and text" capabilities, and thus does not grant access to online social media platforms nor internet-based messaging apps such as Whatsapp. Basic mobile service otherwise shares many similarities with mobile internet coverage. Basic mobile coverage is also more likely to be deployed earlier in denser, wealthier areas and wealthier people may be able to use it more

\footnotetext{
${ }^{24}$ In Table A7 in the appendix, we explore another possible explanation: that the information available for mobile internet users changes their approval of politicians, and this affects their identification with the state. We find no evidence for this explanation.
} 
frequently. We therefore use the effect of basic mobile coverage as a placebo test. Though mobile internet and basic mobile coverage use different technologies and extend different distances, equipment to provide mobile internet coverage is often added to existing cell towers providing basic mobile service. This causes mobile internet coverage and basic mobile service to be spatially correlated. To avoid confounding from mobile internet we restrict the placebo to survey waves prior to the introduction of mobile internet in a country.

Table 5: Placebo test: Heterogeneity of the effect of basic mobile phone service (2G) by election proximity

\begin{tabular}{lcccccc}
\hline \hline & \multicolumn{5}{c}{ Dependent variable: } \\
\cline { 2 - 6 } & $(1)$ & $(2)$ & $(3)$ & $(4)$ & $(5)$ & $(6)$ \\
\hline Basic mobile coverage & 0.051 & 0.045 & 0.029 & 0.025 & 0.046 & 0.046 \\
& $(0.022)^{*}$ & $(0.023)^{*}$ & $(0.022)$ & $(0.022)$ & $(0.042)$ & $(0.042)$ \\
& {$[0.039]$} & {$[0.039]$} & {$[0.034]$} & {$[0.034]$} & {$[0.049]$} & {$[0.049]$} \\
Months from election & -0.002 & -0.002 & -0.003 & -0.003 & -0.002 & -0.002 \\
& $(0.001)^{*}$ & $(0.001)^{*}$ & $(0.001)^{* * *}$ & $(0.001)^{* * *}$ & $(0.002)$ & $(0.002)$ \\
Basic mobile coverage $\times$ & {$[0.002]$} & {$[0.002]$} & {$[0.002]$} & {$[0.002]$} & {$[0.002]$} & {$[0.002]$} \\
Months from election & -0.003 & -0.003 & -0.001 & -0.001 & -0.003 & -0.003 \\
& $(0.001)^{* *}$ & $(0.001)^{*}$ & $(0.001)$ & $(0.001)$ & $(0.002)$ & $(0.002)$ \\
\hline Fixed effects & {$[0.002]$} & {$[0.002]$} & {$[0.002]$} & {$[0.002]$} & {$[0.002]$} & {$[0.003]$} \\
Demographic controls & Country & Country & District & District & Grid cell & Grid cell \\
Observations & No & Yes & No & Yes & No & Yes \\
\hline \hline & 39,247 & 38,717 & 39,247 & 38,717 & 39,247 & 38,717 \\
\hline
\end{tabular}

Notes: Results of a placebo test using access to basic mobile phone service (2G) interacted with proximity to elections. The sample is restricted to the country-waves prior to the intoduction of mobile internet in each country. Robust standard errors clustered at the locality or grid cell level are shown in parentheses. To correct for spatial autocorrelation Conley (1999) standard errors are shown in brackets. ${ }^{*} \mathrm{p}<0.05 ;{ }^{* *} \mathrm{p}<0.01 ;{ }^{* * *} \mathrm{p}<0.001$.

The results are shown in Table 4 and Table 5. Table 4 reports the same specifications as Table 1 but using basic mobile coverage, rather than mobile internet coverage, as treatment. As expected, point estimates are close to zero (albeit positive) and do not reach significance at conventional levels. Table 5 presents the same specifications as Table 2 but with the basic mobile treatment interacted with the months to elections variable. Given that basic mobile coverage does not expose individuals to social media or messaging applications, we expect that the relationship between basic mobile 
coverage and national identity will not be moderated by proximity to elections. In line with these expectations, we find limited evidence of such moderating effects, with the possible exception of columns (1) and (2), which employs a cruder country-fixed effects approach to estimation. Taken together, the findings from the placebo test bolsters our confidence that the effects we reported and mechanisms posited for mobile internet coverage are indeed correct.

\section{Conclusion and Implications}

The expansion of mobile communications infrastructure has been heralded as one of the most transformative innovations of the past century. Whereas the reach of other landmark technological advances is believed to have been relatively limited in the Global South, academics and practitioners alike have shown that cell phone coverage is having a profound impact on these developing societies; on how day-to-day economic transactions are being handled (Suri and Jack, 2016; Aron, 2018) as well as how individuals engage in contentious collective action against the state (Pierskalla and Hollenbach, 2013).

In this paper, we have investigated what effect the expansion of mobile internet has on another salient and important dimension in sociopolitical life: the extent to which individuals share a sense of belonging or attachment to their national community. Leveraging over-time variation in mobile internet coverage in the context of a DiD design, we demonstrated that those with mobile coverage are significantly less likely to identify with their national in comparison to their ethno-communal groups. In addition, we tested the plausibility of the electoral mechanism we posited for the mobile internet effect by exploiting exogenous variation in the proximity of a survey respondent's interview date to the presidential election; our results showed that, as expected, the proximity to elections moderates the effect of mobile internet coverage.

Our findings provide some important avenues for extension. First, further analysis of the mechanisms underlying the negative relationship between cell phone coverage and national identification is warranted. Our approach in testing for the electoral mechanism is based on the assumption that 
the dissemination of such polarizing information is likely to increase as a function of proximity to the elections, which we were ultimately unable to test in the context of this paper. Future research should therefore attempt to validate this assumption by examining both the nature of the information and rhetoric disseminated through mobile cell phone networks, and how it evolves as elections approach.

Second, further analysis into the generalizability of our findings is also necessary. Our results are restricted in the sense that we are only examining the effects of cell phone coverage over a relatively recent time period on a sample of citizens in sub-Saharan African countries, and there may be heterogeneous effects across different time periods and geographical contexts. For example, is the relationship between cell phone coverage and national identification similar across both the nascent stages of cell phone expansion (early 2000s) and later stages in which cell phones are much more ubiquitous? How do the effects of cell phone coverage vary across contexts in which politics are organized along different social cleavages (ethnicity versus class)? An attempt to examine this effect with more data spanning a longer time period and covering different regions of the world would provide more confidence as to the temporal and geographic external validity of these findings. 


\section{References}

Adebanjo, Oluwayemisi. 2019. "Digital Democracy, Analogue Politics: How the Internet Era is Transforming Politics in Kenya." African Studies Quarterly 18(4):85-87.

Aker, Jenny C. 2008. "Does digital divide or provide? The impact of cell phones on grain markets in Niger." Center for Global Development working paper (154).

Aker, Jenny C and Isaac M Mbiti. 2010. "Mobile phones and economic development in Africa." Journal of Economic Perspectives 24(3):207-32.

Allcott, Hunt and Matthew Gentzkow. 2017. "Social media and fake news in the 2016 election." Journal of economic perspectives 31(2):211-36.

Anderson, Benedict. 1983. Imagined Communities: Reflections on the origin and spread of nationalism. Verso Books.

Aron, Janine. 2018. "Mobile money and the economy: A review of the evidence." The World Bank Research Observer 33(2):135-188.

Arriola, Leonardo R. 2012. Multi-Ethnic Coalitions in Africa: Business Financing of Opposition Election Campaigns. New York: Cambridge University Press.

Bates, Robert H. 1974. "Ethnic competition and modernization in contemporary Africa." Comparative Political Studies 6(4):457-484.

Bleck, Jaimie and Kristin Michelitch. 2017. "Capturing the airwaves, capturing the nation? A field experiment on state-run media effects in the wake of a coup." The Journal of Politics 79(3):873889.

Boxell, Levi, Matthew Gentzkow and Jesse M Shapiro. 2017. "Greater Internet use is not associated with faster growth in political polarization among US demographic groups." Proceedings of the National Academy of Sciences 114(40):10612-10617.

Brennan, Geoffrey and Alan Hamlin. 1998. "Expressive voting and electoral equilibrium." Public choice 95(1-2):149-175.

Brierley, Sarah and Eric Kramon. 2020. "party campaign strategies in Ghana: rallies, canvassing and handouts." African Affairs 119(477):587-603.

Cheeseman, Nic, Jonathan Fisher, Idayat Hassan and Jamie Hitchen. 2020. "Social Media Disruption: Nigeria’s WhatsApp Politics." Journal of Democracy 31(3):145-159.

Christensen, Darin and Francisco Garfias. 2018. "Can you hear me now? How communication technology affects protest and repression." Quarterly journal of political science 13(1):89.

Cinelli, Matteo, Gianmarco De Francisci Morales, Alessandro Galeazzi, Walter Quattrociocchi and Michele Starnini. 2021. "The echo chamber effect on social media." Proceedings of the National Academy of Sciences 118(9). 
Colleoni, Elanor, Alessandro Rozza and Adam Arvidsson. 2014. "Echo chamber or public sphere? Predicting political orientation and measuring political homophily in Twitter using big data." Journal of Communication 64(2):317-332.

Conley, Timothy G. 1999. "GMM estimation with cross sectional dependence." Journal of econometrics 92(1):1-45.

Deutsch, Karl Wolfgang. 1966. Nationalism and social communication: An inquiry into the foundations of nationality. Vol. 34 mit Press.

Dobson, Jerome E, Edward A Bright, Phillip R Coleman, Richard C Durfee and Brian A Worley. 2000. "LandScan: a global population database for estimating populations at risk." Photogrammetric engineering and remote sensing 66(7):849-857.

Eifert, Benn, Edward Miguel and Daniel N Posner. 2010. "Political competition and ethnic identification in Africa." American Journal of Political Science 54(2):494-510.

Enikolopov, Ruben, Alexey Makarin and Maria Petrova. 2020. "Social media and protest participation: Evidence from Russia." Econometrica 88(4):1479-1514.

Ezeibe, Christian. 2020. "Hate speech and election violence in Nigeria." Journal of Asian and African Studies p. 0021909620951208.

Ferree, Karen E. 2010. Framing the Race in South Africa: The Political Origins of Racial Census Elections. Cambridge University Press.

Gadjanova, Elena. 2017. "Ethnic wedge issues in electoral campaigns in Africa's presidential regimes." African Affairs 116(464):484-507.

Gellner, Ernest. 2008. Nations and Nationalism. Cornell University Press.

Grinberg, Nir, Kenneth Joseph, Lisa Friedland, Briony Swire-Thompson and David Lazer. 2019. "Fake news on Twitter during the 2016 US presidential election." Science 363(6425):374-378.

Guess, Andrew, Jonathan Nagler and Joshua Tucker. 2019. "Less than you think: Prevalence and predictors of fake news dissemination on Facebook." Science advances 5(1):eaau4586.

Guess, Andrew M. 2021. “(Almost) Everything in Moderation: New Evidence on Americans’ Online Media Diets.”.

Guess, Andrew M., Brendan Nyhan and Jason Reifler. 2020. "Exposure to untrustworthy websites in the 2016 US election." Nature Human Behaviour 4(5):472-480.

Hainmueller, Jens, Jonathan Mummolo and Yiqing Xu. 2019. "How much should we trust estimates from multiplicative interaction models? Simple tools to improve empirical practice." Political Analysis 27(2):163-192.

Halberstam, Yosh and Brian Knight. 2016. "Homophily, group size, and the diffusion of political information in social networks: Evidence from Twitter." Journal of public economics 143:73-88. 
Horowitz, Donald L. 1985. Ethnic Groups in Conflict, Updated Edition With a New Preface. 2nd edition ed. Berkeley, Calif.; London: University of California Press.

Keele, Luke J and Rocio Titiunik. 2015. “Geographic Boundaries as Regression Discontinuities." Political Analysis 23(1):127-155.

Lazer, David MJ, Matthew A Baum, Yochai Benkler, Adam J Berinsky, Kelly M Greenhill, Filippo Menczer, Miriam J Metzger, Brendan Nyhan, Gordon Pennycook, David Rothschild et al. 2018. “The science of fake news." Science 359(6380):1094-1096.

Lelkes, Yphtach, Gaurav Sood and Shanto Iyengar. 2017. “The hostile audience: The effect of access to broadband internet on partisan affect." American Journal of Political Science 61(1):5-20.

Li, Xuecao, Yuyu Zhou, Min Zhao and Xia Zhao. 2020. "A harmonized global nighttime light dataset 1992-2018." Scientific Data 7(1):1-9.

Lupu, Noam, Mariana V Ramírez Bustamante and Elizabeth J Zechmeister. 2020. "Social media disruption: Messaging mistrust in Latin America." Journal of Democracy 31(3):160-171.

Michelitch, Kristin. 2015. "Does electoral competition exacerbate interethnic or interpartisan economic discrimination? Evidence from a field experiment in market price bargaining." American Political Science Review 109(01):43-61.

Mpofu, Shepherd. 2019. "For a nation to progress victims must 'move on': a case of Zimbabwe's social media discourses of Gukurahundi genocide silencing and resistance." African Identities 17(2):108-129.

Muto, Megumi and Takashi Yamano. 2009. “The impact of mobile phone coverage expansion on market participation: Panel data evidence from Uganda." World development 37(12):1887-1896.

Mutz, Diana C and Paul S Martin. 2001. "Facilitating communication across lines of political difference: The role of mass media." American Political Science Review 95(1):97-114.

Ncube, Lyton. 2019. "Digital Media, Fake News and Pro-Movement for Democratic Change (MDC) Alliance Cyber-Propaganda during the 2018 Zimbabwe Election.” African Journalism Studies pp. 1-18.

Nyabola, Nanjala. 2018. Digital democracy, analogue politics: How the Internet era is transforming politics in Kenya. Zed Books Ltd.

Peisakhin, Leonid and Arturas Rozenas. 2018. "Electoral effects of biased media: Russian television in Ukraine.” American Journal of Political Science 62(3):535-550.

Pew Research Center. 2018. "Internet Connectivity Seen as Having Positive Impact on Life in SubSaharan Africa." p. 51.

Pierskalla, Jan H and Florian M Hollenbach. 2013. "Technology and collective action: The effect of cell phone coverage on political violence in Africa." American Political Science Review 107(2):207224. 
Posner, Daniel N. 2004. “The political salience of cultural difference: Why Chewas and Tumbukas are allies in Zambia and adversaries in Malawi." American Political Science Review 98(04):529545.

Rajput, Himanshu. 2014. "Social media and politics in India: A study on Twitter usage among Indian Political Leaders." Asian Journal of Multidisciplinary Studies 2(1):63-69.

Robinson, Amanda Lea. 2014. "National Versus Ethnic Identification in Africa: Modernization, Colonial Legacy, and the Origins of territorial Nationalism." World Politics 66(04):709-746.

Sambanis, Nicholas and Moses Shayo. 2013. "Social identification and ethnic conflict." American Political Science Review 107(2):294-325.

Settle, Jaime E. 2018. Frenemies: How social media polarizes America. Cambridge University Press.

Suri, Tavneet and William Jack. 2016. "The long-run poverty and gender impacts of mobile money." Science 354(6317):1288-1292.

Vosoughi, Soroush, Deb Roy and Sinan Aral. 2018. "The spread of true and false news online." Science 359(6380):1146-1151.

Weber, Eugen. 1976. Peasants into Frenchmen: the modernization of rural France, 1870-1914. Stanford University Press.

Wilkinson, Steven I. 2006. Votes and violence: Electoral competition and ethnic riots in India. Cambridge University Press. 


\section{A Supporting Information (SI Appendix) for Mobile Communication Technology and National Identity in Sub-Saharan Africa}

\section{Contents}

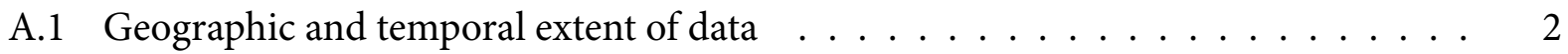

A.2 Results with alternate dependent variables $\ldots \ldots \ldots \ldots \ldots \ldots$

A.3 Additional validation: Boundary design $\ldots \ldots \ldots \ldots$

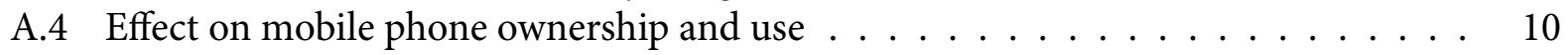

A.5 Distribution of election proximity variable $\ldots \ldots \ldots \ldots \ldots$

A.6 Additional robustness checks . . . . . . . . . . . . . . . . . . . . 14

A.7 Parallel trends . . . . . . . . . . . . . . . . . . . . . 17

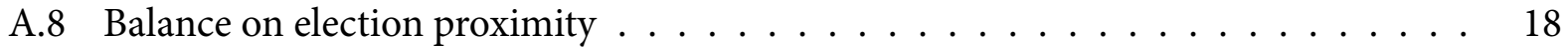

A.9 Alternate outcome: "My ethnic group is treated unfairly" . . . . . . . . . . . . 19 


\section{A.1 Geographic and temporal extent of data}

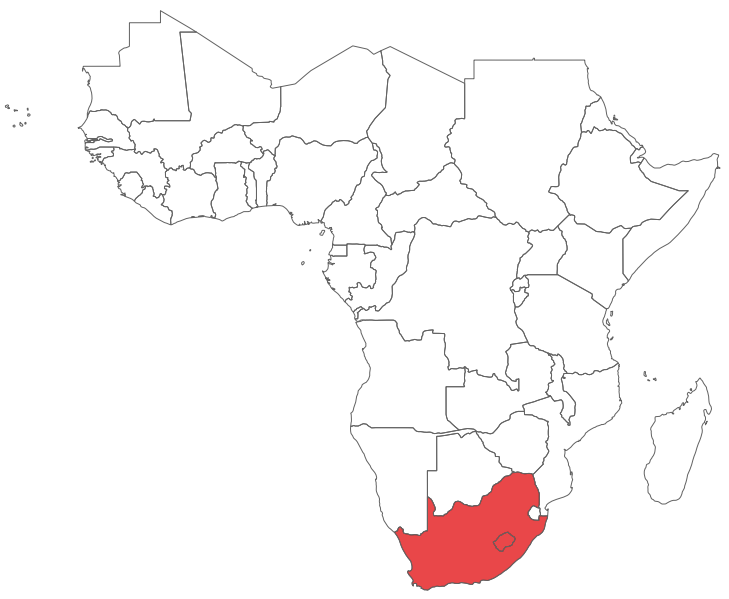

Afrobarometer Round 4

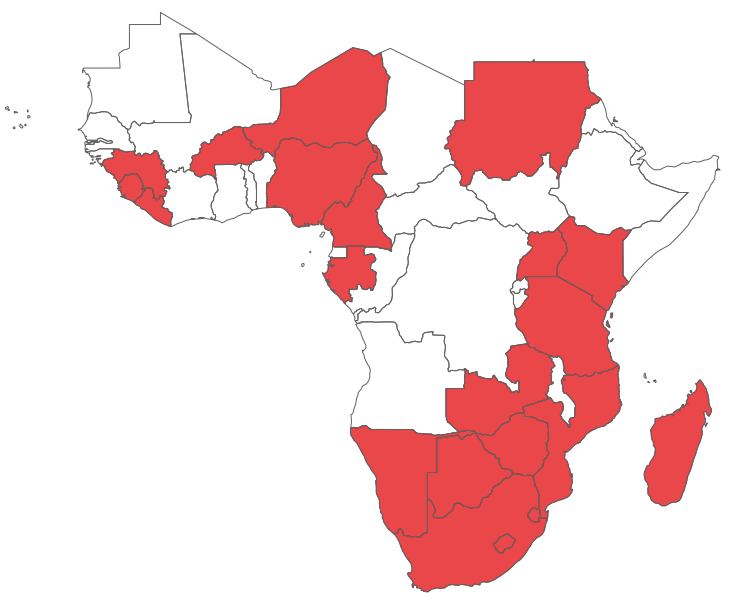

Afrobarometer Round 6

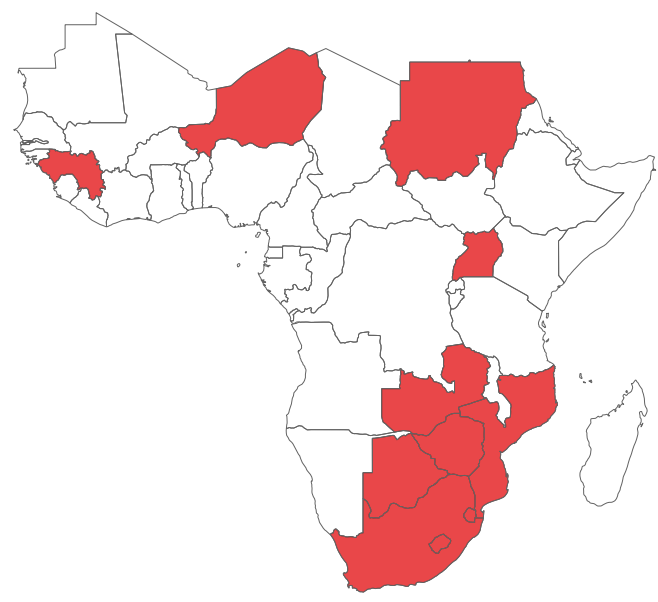

Afrobarometer Round 5

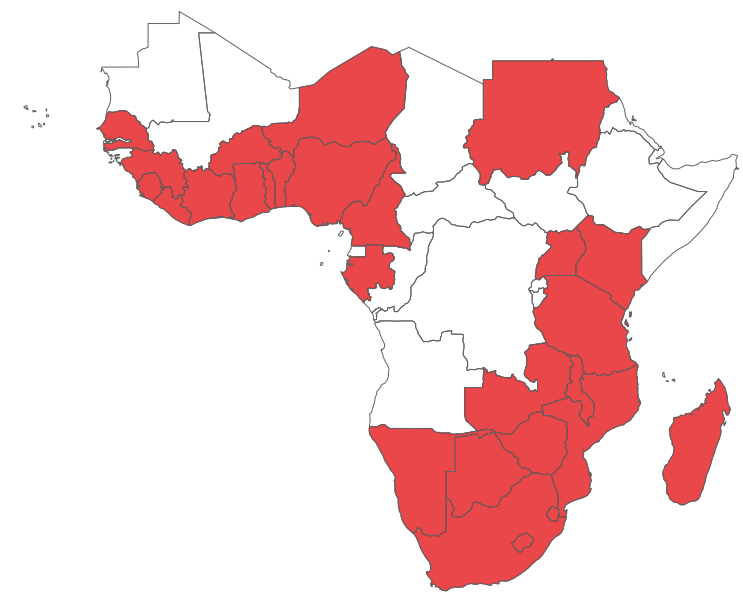

Afrobarometer Round 7

Figure A1: Countries included in each Afrobarometer survey round for which mobile internet coverage data is available from the GSMA. 


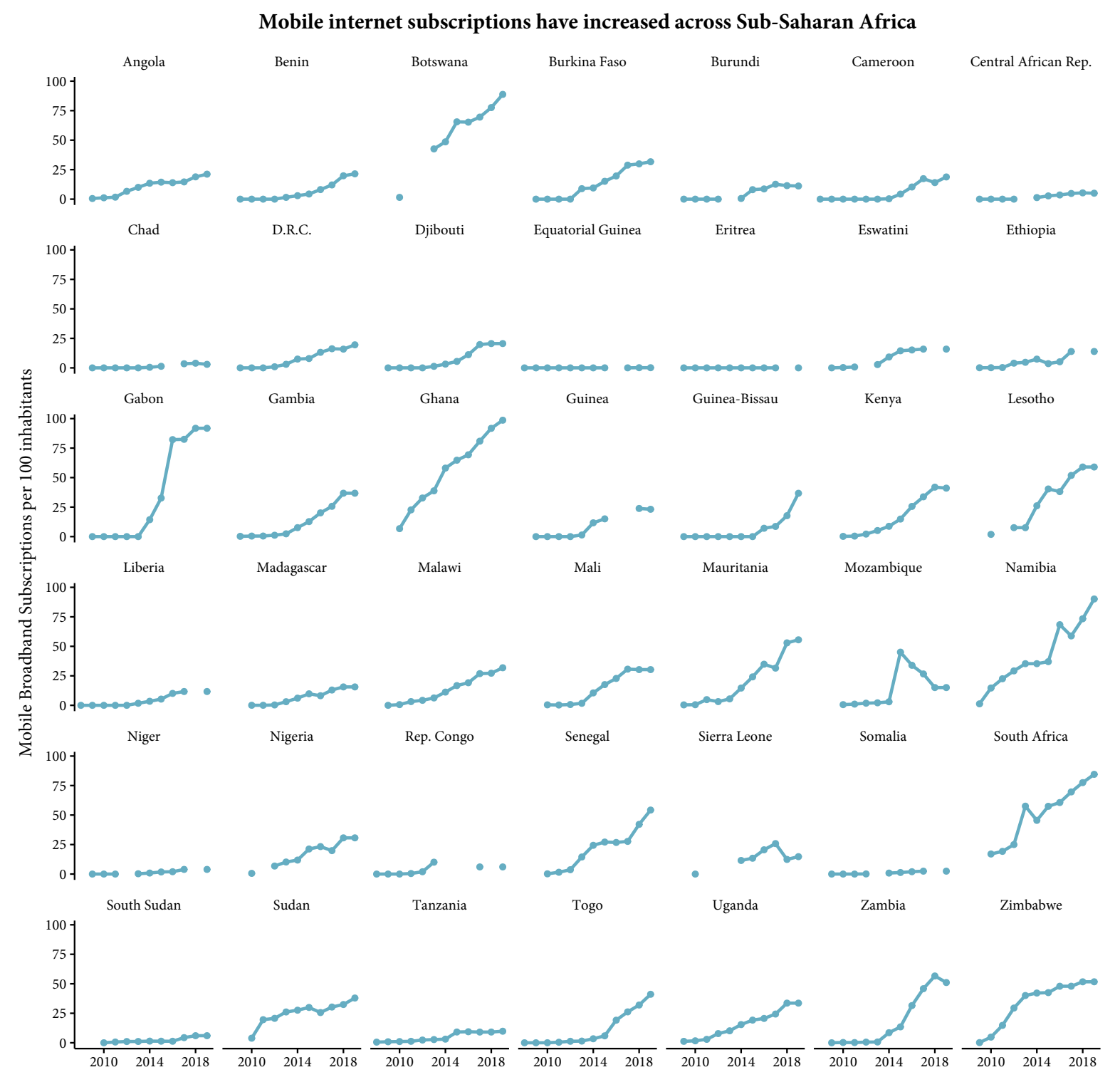

Figure A2: Mobile internet has shown tremendous growth in Sub-Saharan Africa since 2008. The number of mobile internet subscriptions per 100 inhabitants is shown between 2008 and 2019 using data from the International Telecommunications Union. Mobile internet subscriptions increased in every country in Sub-Saharan Africa except Eritrea. 

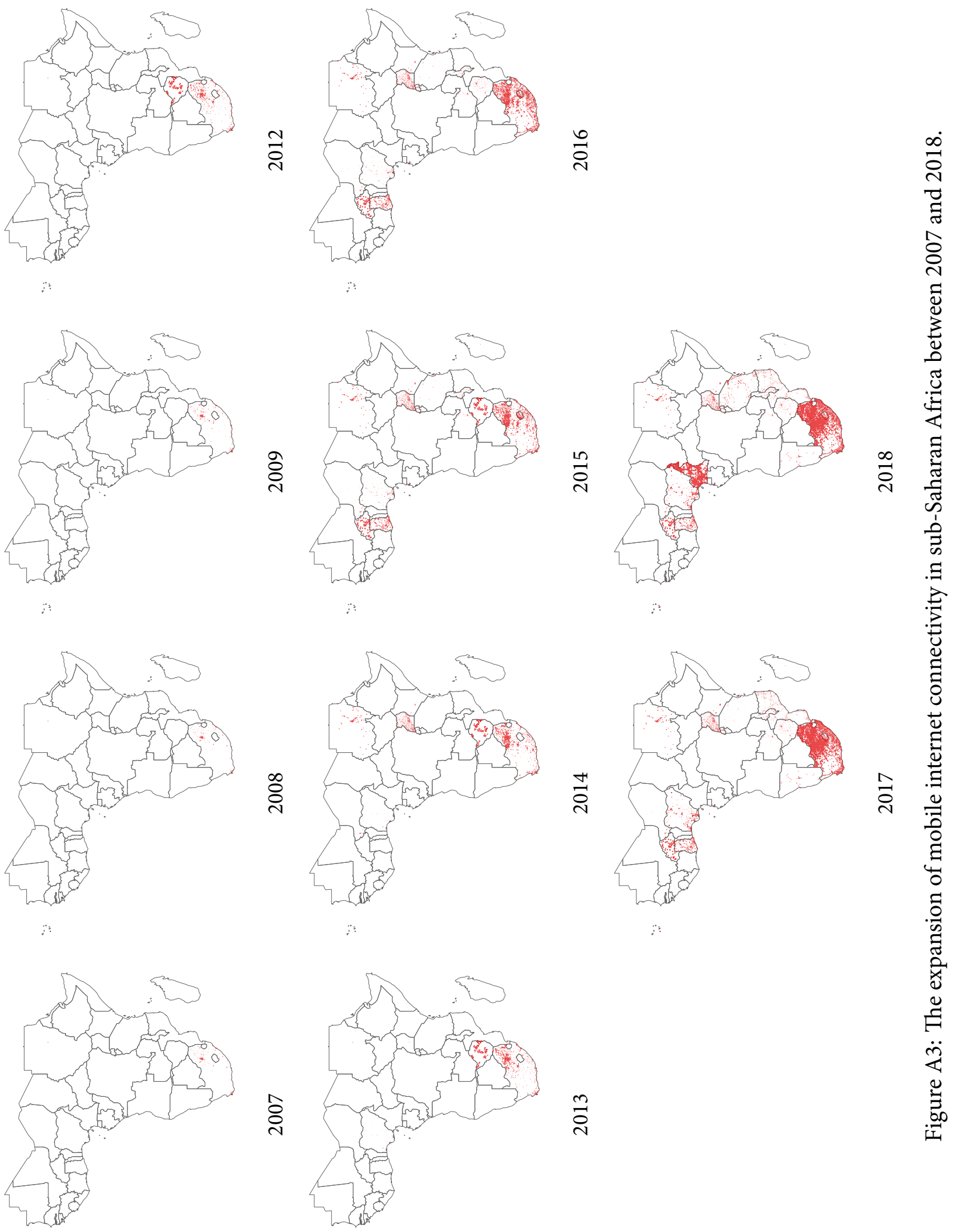

웅 


\section{A.2 Results with alternate dependent variables}

In the main body of the paper we show results in which our main outcome of interest is a respondent answering that they feel a stronger national than ethnic identity. As described in the main body of the paper, this variable was constructed from a question asking "Let us suppose that you had to choose between being a [respondent's national ID] and being a [respondent's ethnic group]. Which of the following best expresses your feelings?" Responses range from 1 ("I feel only [ethnic ID]") to 5 ("I feel only [national ID]"). Our preferred outcome variable is an indicator for whether the respondent identifies more nationally than ethnically: a response of 4 or 5 . The strength of national (versus ethnic) identity could be measured other ways. Tables A1, A2 and A3 show estimates of the same specifications using the raw 5-point scale as the dependent variable.

Table A1: Effect of mobile internet coverage on national identity (5-point scale)

\begin{tabular}{lcccccc}
\hline \hline & \multicolumn{5}{c}{ Dependent variable: } \\
\cline { 2 - 7 } & $(1)$ & $(2)$ & $(3)$ & $(4)$ & $(5)$ & $(6)$ \\
\hline Mobile internet & $-0.148^{* * *}$ & $-0.166^{* * *}$ & $-0.140^{* * *}$ & $-0.147^{* * *}$ & $-0.162^{* * *}$ & $-0.165^{* * *}$ \\
& $(0.026)$ & $(0.026)$ & $(0.024)$ & $(0.024)$ & $(0.044)$ & $(0.044)$ \\
\hline Fixed effects & Country & Country & District & District & Grid cell & Grid cell \\
Demographic controls & No & Yes & No & Yes & No & Yes \\
Observations & 55,238 & 54,809 & 55,238 & 54,809 & 55,238 & 54,809 \\
\hline \hline
\end{tabular}

Notes: Difference in differences results show the effect of mobile internet on a respondent identifying more nationally than ethnically. These results use an alternate measure of national identity as the dependent variable. Here the dependent variable is a five point scale ranging from 1 , for individuals who identify fully ethnically, to 5 , for individuals who identify fully nationally. All specifications include fixed effects for survey wave and either country, district, or grid cell. Columns 5 and 6 aggregate the treatment to $0.5 \times 0.5$ degree grid cells to enable two way fixed effects. Demographic controls include individual-level measures of gender, age, completion of secondary education, and whether their residence is classified as urban or rural by Afrobarometer. Robust standard errors clustered at the locality or grid cell level are shown in parentheses. ${ }^{*} \mathrm{p}<0.05 ;{ }^{* *} \mathrm{p}<0.01 ;{ }^{* * *} \mathrm{p}<0.001$. 
Table A2: Heterogeneity of the effect of mobile internet coverage by election proximity (5-point scale)

\begin{tabular}{lcccccc}
\hline \hline & \multicolumn{5}{c}{ Dependent variable: } \\
\cline { 2 - 6 } & $(1)$ & $(2)$ & $(3)$ & $(4)$ & $(5)$ & $(6)$ \\
\hline Mobile internet & $-0.321^{* * *}$ & $-0.331^{* * *}$ & $-0.340^{* * *}$ & $-0.344^{* * *}$ & $-0.401^{* * *}$ & $-0.411^{* * *}$ \\
& $(0.039)$ & $(0.039)$ & $(0.037)$ & $(0.037)$ & $(0.068)$ & $(0.068)$ \\
Months from election & $-0.006^{* * *}$ & $-0.006^{* * *}$ & $-0.007^{* * *}$ & $-0.007^{* * *}$ & $-0.007^{* * *}$ & $-0.008^{* * *}$ \\
& $(0.001)$ & $(0.001)$ & $(0.001)$ & $(0.001)$ & $(0.002)$ & $(0.002)$ \\
Mobile internet $\times$ & $0.011^{* * *}$ & $0.010^{* * *}$ & $0.013^{* * *}$ & $0.012^{* * *}$ & $0.016^{* * *}$ & $0.016^{* * *}$ \\
Months from election & $(0.002)$ & $(0.002)$ & $(0.002)$ & $(0.002)$ & $(0.005)$ & $(0.005)$ \\
\hline Fixed effects & Country & Country & District & District & Grid cell & Grid cell \\
Demographic controls & No & Yes & No & Yes & No & Yes \\
Observations & 55,238 & 54,809 & 55,238 & 54,809 & 55,238 & 54,809 \\
\hline \hline
\end{tabular}

Notes: Difference in differences estimates of the heterogeneous effects of access to mobile internet on individuals' propensity to identify more nationally than ethnically by proximity to elections are shown. These results use an alternate measure of national identity as the dependent variable. Here the dependent variable is a five point scale ranging from 1 , for individuals who identify fully ethnically, to 5 , for individuals who identify fully nationally. The positive interaction between mobile internet and months from the election indicates that the effect of mobile internet on national identification gets weaker closer to elections. All specifications include fixed effects for survey wave and either country, district, or grid cell. Columns 5 and 6 aggregate the treatment to the $0.5 \times 0.5$ degree grid cell to enable two way fixed effects. Demographic controls include individual-level measures of gender, age, completion of secondary education, and whether their residence is classified as urban or rural by Afrobarometer. Robust standard errors clustered at the locality or grid cell level are shown in parentheses. ${ }^{*} \mathrm{p}<0.05 ;{ }^{* *} \mathrm{p}<0.01 ;{ }^{* * *} \mathrm{p}<0.001$. 


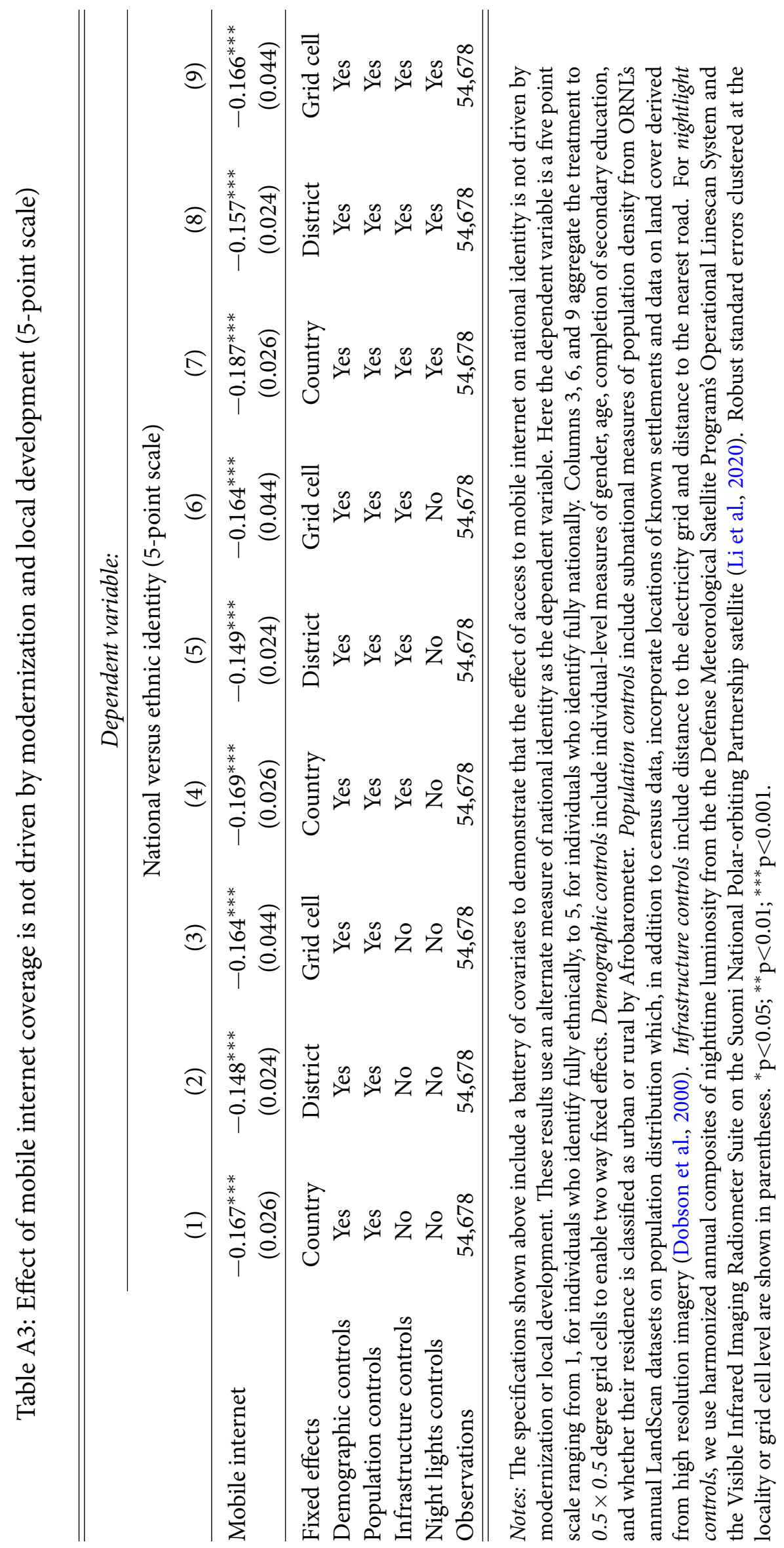




\section{A.3 Additional validation: Boundary design}

In addition to robustness and placebo tests presented in the preceding paragraphs, we also leverage an alternate research design that uses the boundary of mobile internet coverage, comparing individuals with and without access to mobile internet residing within different bandwidths around the boundary of mobile phone coverage. The boundary of mobile internet coverage is a function of the location of cell towers and terrain. Importantly, the mobile internet coverage boundary does not correspond to the borders of administrative units, where other policies and political histories may change discontinuously. However, a geographic regression discontinuity design as in Keele and Titiunik (2015) is not appropriate because the coverage boundary does not represent a sharp discontinuity in mobile phone ownership and usage. Individuals living in areas without coverage that are nonetheless near the coverage boundary do have some access to mobile networks as they travel in and out of coverage boundaries as they go about their daily lives, but they have less access to mobile networks than individuals living in covered areas.

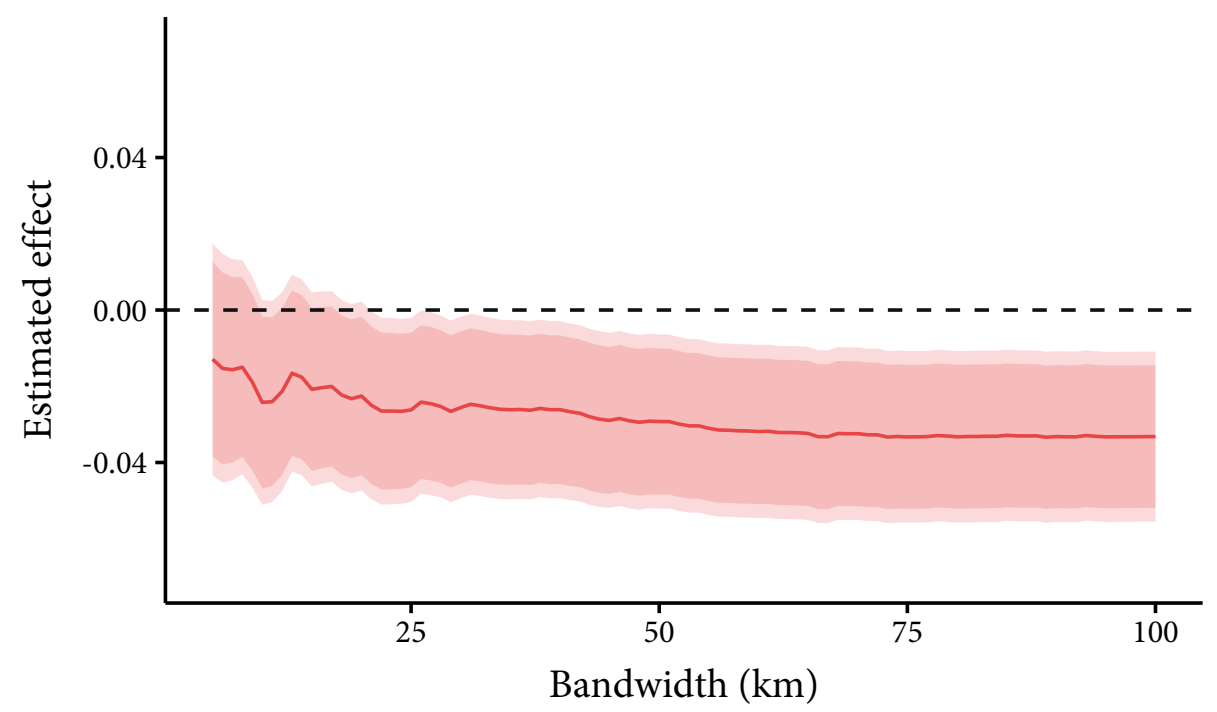

Figure A4: Results of the boundary analysis, showing how the propensity to identify more nationally than ethnically varies across the 3G coverage boundaries for a variety of bandwidths. 90 and 95 percent confidence intervals clustered by locality are shown.

We estimate the effect of mobile phone coverage on national identity using the following specification, comparing the national identity of respondents on either side of the mobile internet coverage boundary:

$$
y_{i j t}=\alpha+\beta \text { Covered }_{i}+\delta_{j t}+\xi W_{i}+\theta X_{i j}+\varepsilon_{i j t}
$$

where $y_{i j t}$ is an outcome for individual $i$ in geographic area $j$ in time period $t$ and Covered is an indicator variable for whether the individual has mobile internet coverage. The border design is cross-sectional, so we include country-wave fixed effects, designated $\delta_{j t}$. A flexibly estimated expansion of latitude and longitude, $W_{i}$ is also included. Again we cluster standard errors at the locality level. For the cross boundary comparison to be possible, there must be sufficient numbers of respondents in a country-wave on either side of the boundary-with and without coverage. 
Therefore, we restrict the boundary analysis to country-waves in which at least 10 respondents have mobile internet coverage and at least 10 respondents do not have coverage.

Figure A4 graphically reports results from these analyses, showing the difference in national identity for respondents with and without coverage residing near the coverage boundary for range of bandwidths between $5 \mathrm{~km} \sim 100 \mathrm{~km} .{ }^{1}$ Although there is a significant reduction in sample size, we are able to recover a negative treatment effect of mobile internet coverage on levels of national identification. The magnitude of the point estimates decreases for smaller bandwidths, consistent with the coverage boundaries not representing sharp discontinuities in actual mobile internet usage. However, point estimates remain negative and statistically significant over a broad spectrum of bandwidths.

\footnotetext{
${ }^{1}$ Because population, and thus country-wide survey sampling, is often sparse along the coverage boundary, we show a wide range of bandwidths.
} 


\section{A.4 Effect on mobile phone ownership and use}

A necessary condition of the mechanism we propose is that mobile internet coverage must cause an increase in use of mobile internet. Although we are unable to test this idea directly, we instead evaluate the effect of mobile internet coverage on self-reports of mobile phone ownership, mobile phone use, and where a respondent has a mobile internet subscription. Of these, mobile phone ownership is most weakly linked to our mechanism. This is because basic mobile phone can be used by respondents to talk and text who do not use mobile internet. Using a mobile phone daily is potentially more closely linked to our proposed mechanism, because the ability to use a phone for things other than talk or text may lead to more use. Table A4 shows difference-in-differences estimates of the effect of mobile internet on mobile phone ownership and use. Specifications with and without a one period lead are shown. Results indicate that that mobile internet coverage causes an increase in increase in daily use of mobile phones, but the effect on mobile phone ownership is more ambiguous. Future mobile coverage does not appear to affect mobile phone ownership or use.

Several measures of mobile internet use are only available in Afrobarometer round 7 and, therefore, cannot be used in the context of a DiD design. We instead show boundary analysis results for these outcomes, following the methodology described in SI Appendix Section A.3. SI Appendix Figures A5, A6, A7, A8, and A9 show boundary analysis results within a variety of bandwidths from the mobile internet coverage boundary, estimating the effect of mobile internet coverage on having a mobile internet subscription, getting news from social media such as Facebook or Twitter, getting news from the internet, using a mobile phone daily, and owning a mobile phone. Results indicate that mobile internet coverage causes a significant increase in all five outcomes.

Table A4: Effect of mobile internet on mobile phone ownership and use

\begin{tabular}{lcccc}
\hline \hline & \multicolumn{4}{c}{ Dependent variable: } \\
\cline { 2 - 5 } & Owns mobile phone & Uses mobile daily \\
& $(1)$ & $(2)$ & $(3)$ & $(4)$ \\
\hline Mobile internet coverage & 0.017 & $0.037^{* *}$ & $0.041^{* * *}$ & $0.091^{* * *}$ \\
& $(0.011)$ & $(0.017)$ & $(0.014)$ & $(0.023)$ \\
Mobile internet coverage $(\mathrm{t}+1)$ & & -0.037 & & -0.021 \\
& & $(0.024)$ & & $(0.027)$ \\
\hline Fixed effects & Country & Country & Country & Country \\
Observations & 57,018 & 18,746 & 40,291 & 11,886 \\
\hline \hline
\end{tabular}

Notes: Difference-in-differences estimates of the effect of mobile internet coverage on mobile phone ownership and use. Robust standard errors clustered at the locality level are shown in parentheses. ${ }^{*} \mathrm{p}<0.05 ;{ }^{* *} \mathrm{p}<0.01 ;{ }^{* * *} \mathrm{p}<0.001$. 
Dependent variable: Mobile internet subscription

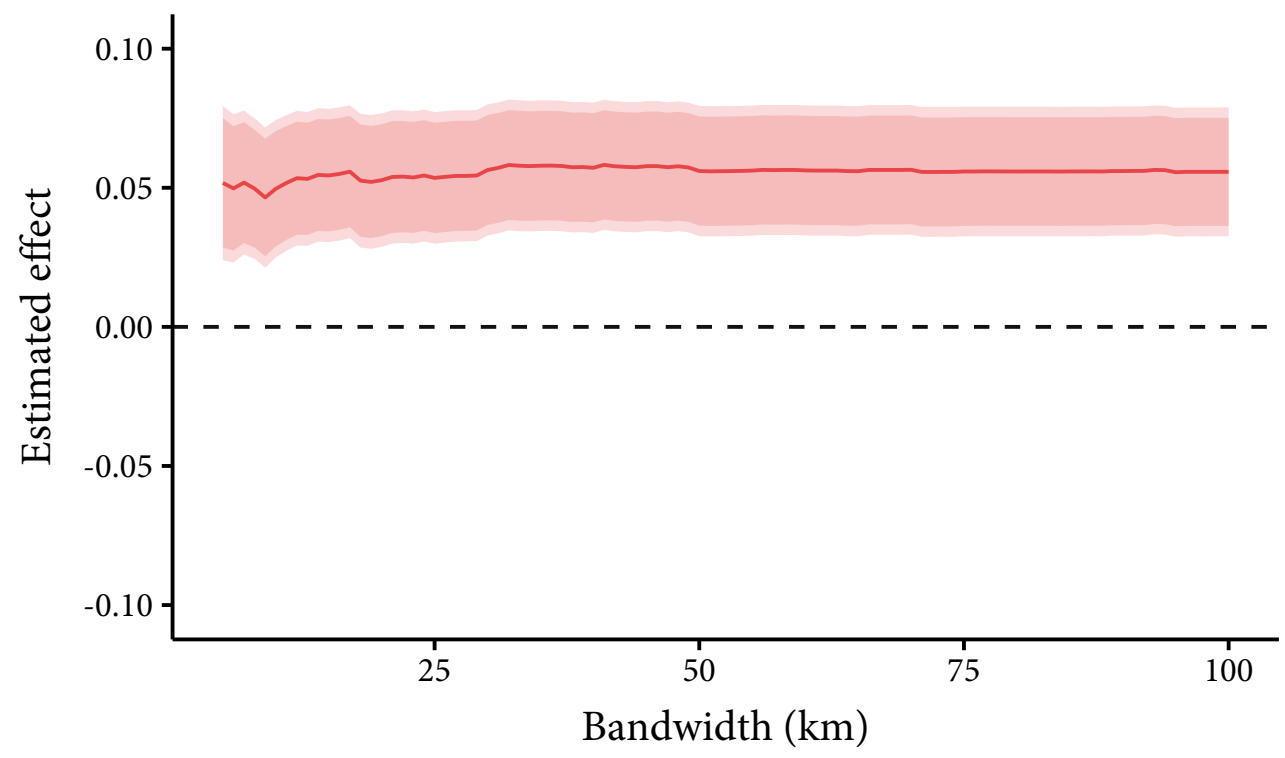

Figure A5: Results of the boundary analysis, showing how the propensity of a respondent to have a mobile internet subscription varies across the $3 \mathrm{G}$ coverage boundaries for a variety of bandwidths. 90 and 95 percent confidence intervals clustered by locality are shown.

Dependent variable: News from social media

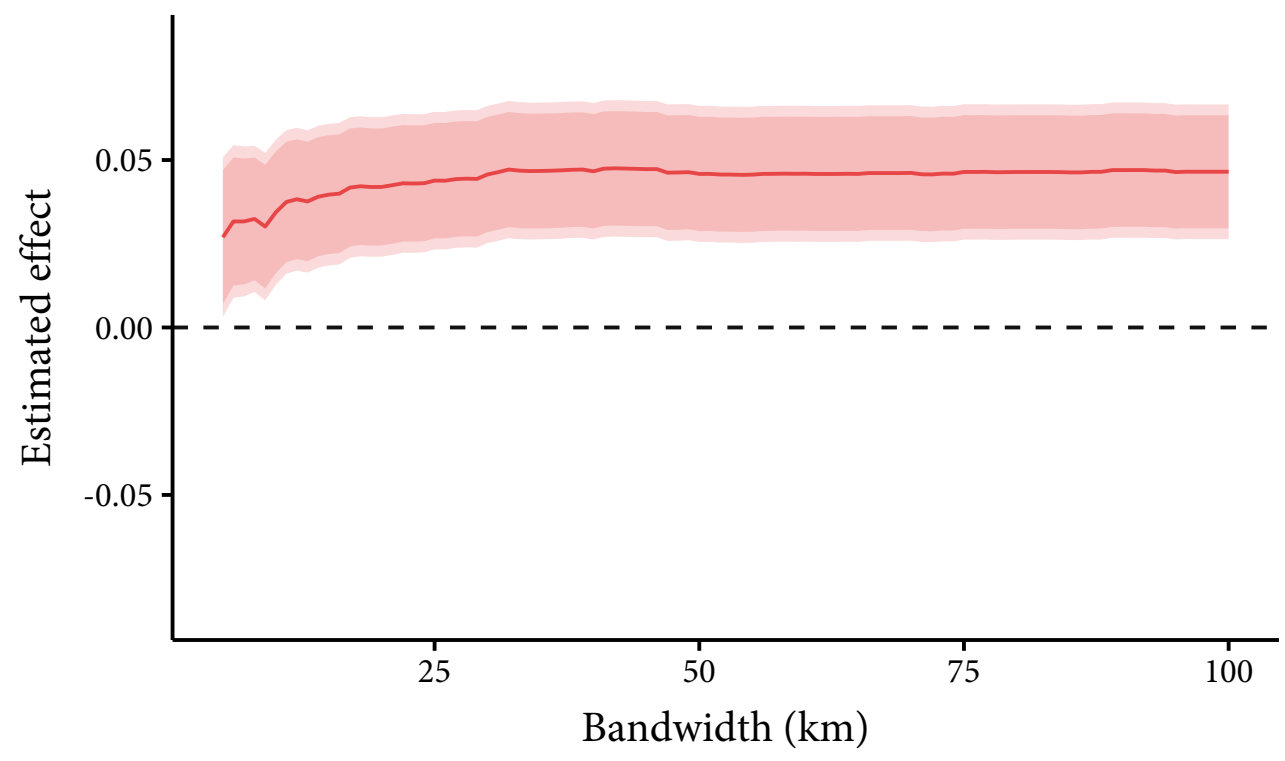

Figure A6: Results of the boundary analysis, showing how the propensity of a respondent to get news from social media varies across the $3 \mathrm{G}$ coverage boundaries for a variety of bandwidths. 90 and 95 percent confidence intervals clustered by locality are shown. 
Dependent variable: News from internet

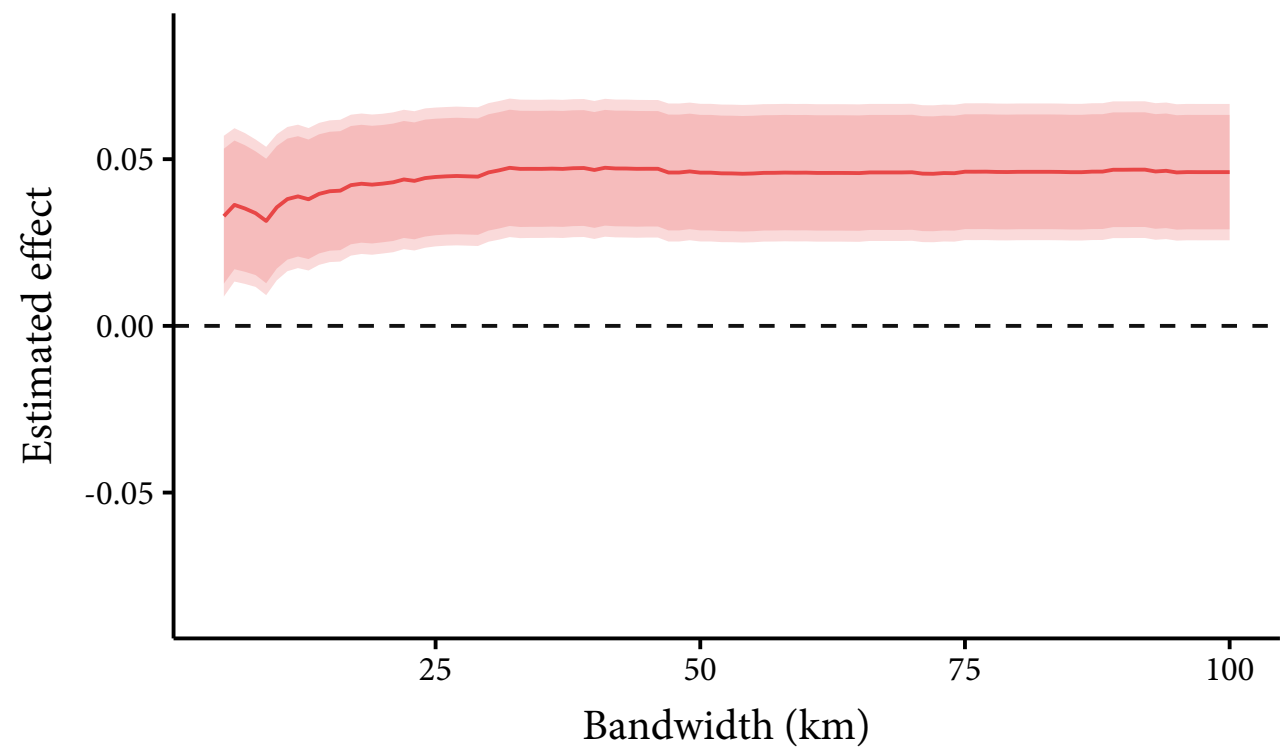

Figure A7: Results of the boundary analysis, showing how the propensity of a respondent to get news from the internet varies across the $3 \mathrm{G}$ coverage boundaries for a variety of bandwidths. 90 and 95 percent confidence intervals clustered by locality are shown.

Dependent variable: Use mobile phone daily

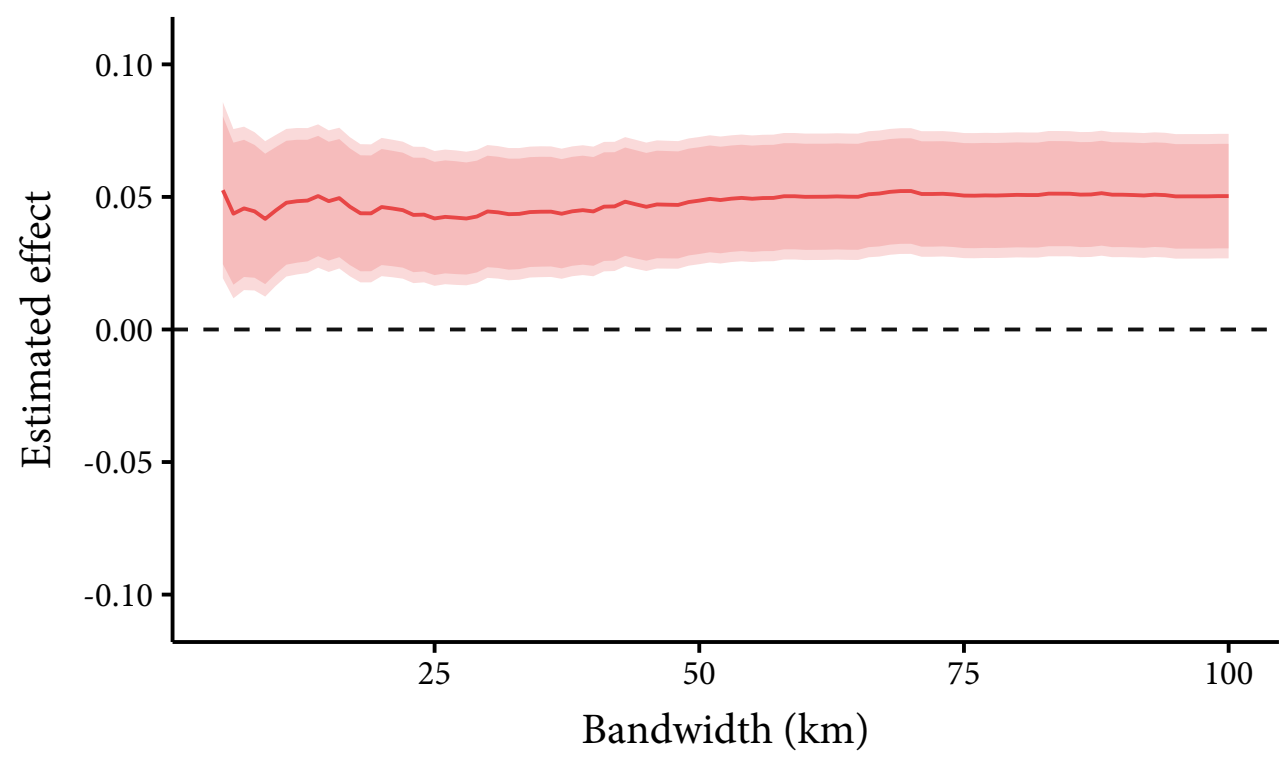

Figure A8: Results of the boundary analysis, showing how the propensity of a respondent to use a mobile phone daily varies across the $3 \mathrm{G}$ coverage boundaries for a variety of bandwidths. 90 and 95 percent confidence intervals clustered by locality are shown. 
Dependent variable: Own mobile phone

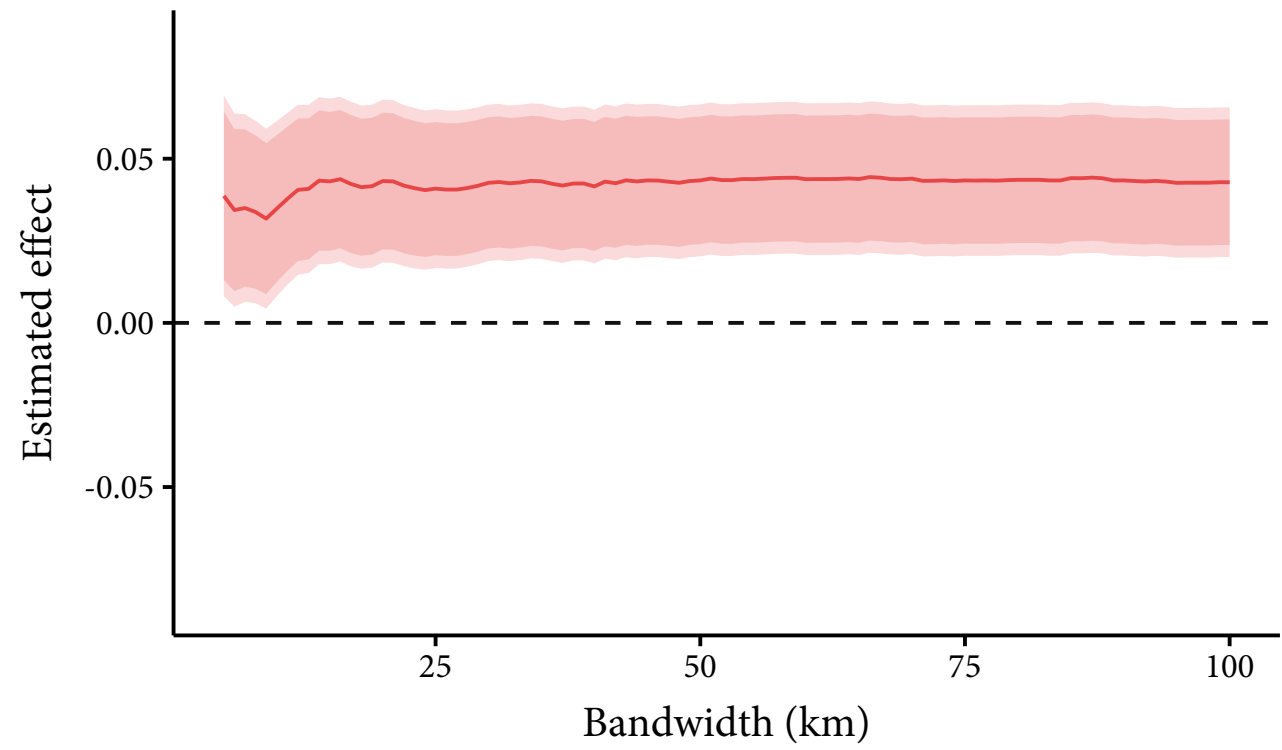

Figure A9: Results of the boundary analysis, showing how the propensity of a respondent to own a mobile phone varies across the $3 \mathrm{G}$ coverage boundaries for a variety of bandwidths. 90 and 95 percent confidence intervals clustered by locality are shown.

\section{A.5 Distribution of election proximity variable}

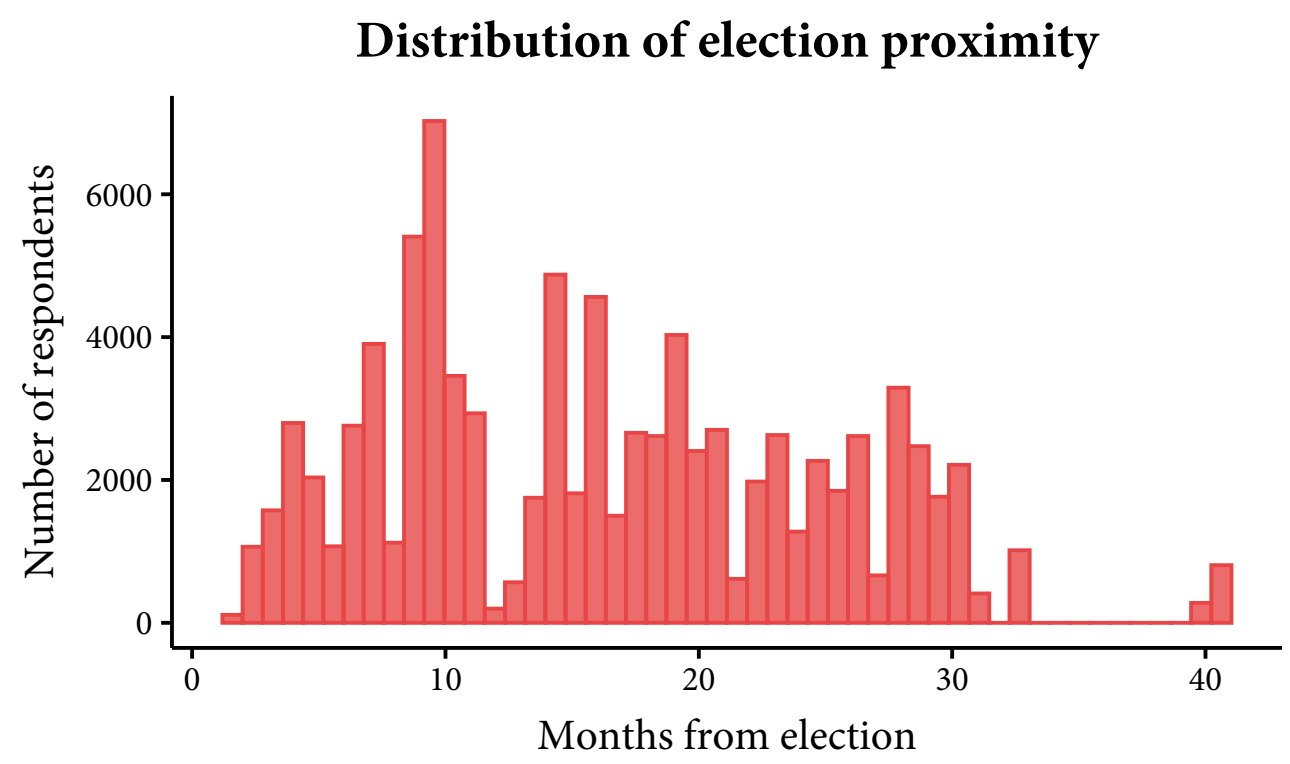

Figure A10: The distribution of months to the nearest election across respondents 


\section{A.6 Additional robustness checks}

Table A5 estimates the effect of mobile internet on identity and includes controls for measures of individual wealth and media consumption. Table A6 shows results for the interaction between mobile internet and election proximity, and includes controls for multiple measures of modernization and local development.

Table A5: Effect of mobile internet coverage on national identity

\begin{tabular}{lcccccc}
\hline \hline & \multicolumn{5}{c}{ Dependent variable: } \\
\cline { 2 - 7 } & \multicolumn{7}{c}{ Identify More Nationally } & Than Ethnically (Binary) \\
& $(1)$ & $(2)$ & $(3)$ & $(4)$ & $(5)$ & $(6)$ \\
\hline Mobile internet & $-0.067^{* * *}$ & $-0.058^{* * *}$ & $-0.063^{* * *}$ & $-0.066^{* * *}$ & $-0.057^{* * *}$ & $-0.062^{* * *}$ \\
& $(0.011)$ & $(0.010)$ & $(0.019)$ & $(0.011)$ & $(0.010)$ & $(0.019)$ \\
\hline Fixed effects & Country & District & Grid cell & Country & District & Grid cell \\
Demographic controls & Yes & Yes & Yes & Yes & Yes & Yes \\
Wealth controls & Yes & Yes & Yes & No & No & No \\
Media controls & No & No & No & Yes & Yes & Yes \\
Observations & 54,303 & 54,303 & 54,303 & 54,484 & 54,484 & 54,484 \\
\hline \hline
\end{tabular}

Notes: Difference in differences results show the effect of mobile internet on a respondent identifying more nationally than ethnically. All specifications include fixed effects for survey wave and either country, district, or grid cell. Columns 3 and 6 aggregate the treatment to $0.5 \times 0.5$ degree grid cells to enable two way fixed effects. Demographic controls include individual-level measures of gender, age, completion of secondary education, and whether their residence is classified as urban or rural by Afrobarometer. Wealth controls include an index of asset ownership as reported in the Afrobarometer surveys. Survey items probed whether a respondent owned a radio, TV, or motor vehicle. We include an index created from the dichotomous measure of each asset ownership. Media controls includes individual-level measures of news consumption from newspapers, radio, and television as reported in the Afrobarometer surveys. Robust standard errors clustered at the locality or grid cell level are shown in parentheses. ${ }^{*} \mathrm{p}<0.05 ;{ }^{* *} \mathrm{p}<0.01 ;{ }^{* * *} \mathrm{p}<0.001$. 


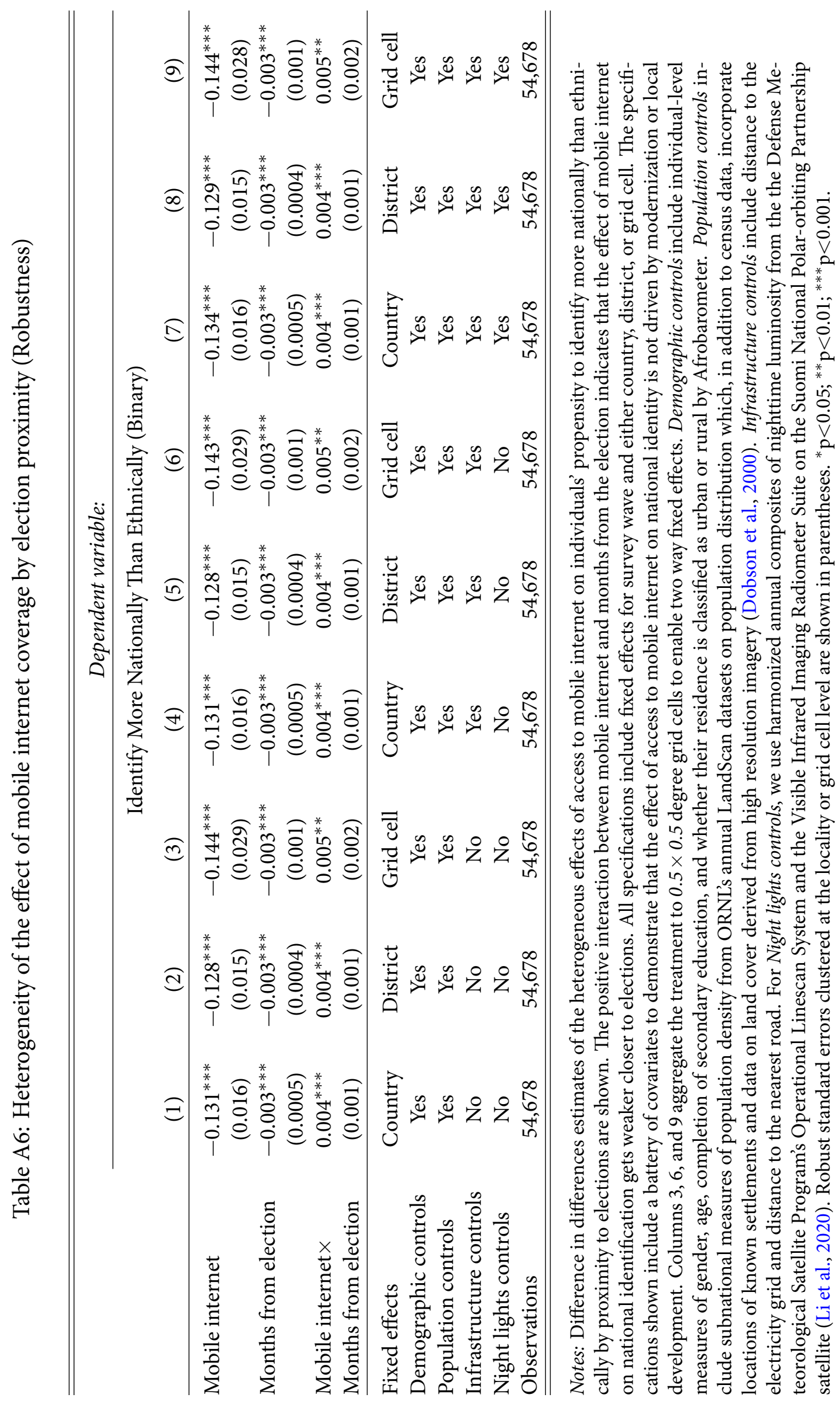


Table A7: Effect of access to mobile coverage is not driven by approval of and trust in government

\begin{tabular}{|c|c|c|c|c|c|c|}
\hline & \multicolumn{6}{|c|}{ Dependent variable: } \\
\hline & \multicolumn{6}{|c|}{ Identify More Nationally Than Ethnically (Binary) } \\
\hline & $(1)$ & $(2)$ & $(3)$ & $(4)$ & $(5)$ & (6) \\
\hline Mobile internet & $\begin{array}{c}-0.039^{* * *} \\
(0.012)\end{array}$ & $\begin{array}{c}-0.031^{* *} \\
(0.011)\end{array}$ & $\begin{array}{l}-0.020 \\
(0.021)\end{array}$ & $\begin{array}{c}-0.065^{* * *} \\
(0.011)\end{array}$ & $\begin{array}{c}-0.058^{* * *} \\
(0.010)\end{array}$ & $\begin{array}{c}-0.059^{* *} \\
(0.019)\end{array}$ \\
\hline Fixed effects & Country & District & Grid cell & Country & District & Grid cell \\
\hline Demographic controls & Yes & Yes & Yes & Yes & Yes & Yes \\
\hline Gov. approval controls & Yes & Yes & Yes & No & No & No \\
\hline Gov. trust controls & No & No & No & Yes & Yes & Yes \\
\hline Observations & 45,073 & 45,073 & 45,073 & 51,331 & 51,331 & 51,331 \\
\hline
\end{tabular}

Notes: Difference in differences results show the effect of mobile internet on a respondent identifying more nationally than ethnically. These models include controls for approval of and trust in government officials and institutions. Columns 3 and 6 aggregate the treatment to $0.5 \times 0.5$ degree grid cells to enable two way fixed effects. All specifications include fixed effects for survey wave and either country or district. Government approval controls are individual-level measures of approval of the president and the respondent's MP, each on a 4-point scale. Government trust controls are individual-level measures of trust in the president and parliament, also each on a 4-point scale. Demographic controls include individual-level measures of gender, age, completion of secondary education, and whether their residence is classified as urban or rural by Afrobarometer. Robust standard errors clustered at the locality or grid cell level are shown in parentheses. ${ }^{*} \mathrm{p}<0.05 ;{ }^{* *} \mathrm{p}<0.01 ;{ }^{* * *} \mathrm{p}<0.001$.

Table A7 adds controls for approval of and trust in government officials to table 1 in order to examine whether results for the effect of mobile internet on national identification could be driven by changes in approval of and trust in government officials and institutions that may accompany access to mobile internet. Columns 1 and 2 include controls for respondents' approval of the president and their MP, each measured on a 4-point scale. Columns 3 and 4 include controls for respondents' trust in the president the parliament, which are both also measured on a 4-point scale. The effect of mobile internet remains negative and statistically significant with these controls. These variables are post-treatment, so caution is warranted in interpreting these estimates. However, these results provides evidence that changes in approval and trust in government are unlikely to be driving the effect of mobile internet on national identity. 


\section{A.7 Parallel trends}

The difference-in-differences estimator relies on the assumption of parallel trends-that national identification in treated and untreated areas would have followed similar patterns absent treatment. Though this assumption is untestable, its plausibility is often assessed using pre-treatment trends. Differential trends between treatment and control groups prior to actual changes in coverage would suggest that differential trends during the treatment period could be driven by other factors. For instance, one alternative explanation for our finding of decreased national identification is that mobile internet providers expand coverage into wealthy areas, and that this economic development itself, rather than mobile coverage, causes decreases in national identification. We test whether differences in national identity precede changes in coverage by estimating equation 1 with the addition of one and two period leads to the treatment variable. That is, we include respondent's treatment status for the survey waves that occur after after the actual interview. Results are shown in Table A8. In all specifications the effect of mobile internet coverage on a respondent identifying more nationally than ethnically remains negative and statistically significant at conventional levels. Coefficients for the leads of mobile internet coverage, representing the effect of future mobile internet coverage on current national identity, have point estimates near zero and are not significant at conventional levels. These results suggest that national identification does not anticipate mobile coverage, which we interpret to mean that our findings are not the result of mobile coverage expanding into more affluent areas.

Table A8: Future mobile internet does not cause a reduction in national identity

\begin{tabular}{lcccccc}
\hline \hline & \multicolumn{5}{c}{ Dependent variable: } \\
\cline { 2 - 7 } & $(1)$ & $(2)$ & $(3)$ & $(4)$ & $(5)$ & $(6)$ \\
\hline Mobile internet & $-0.101^{*}$ & $-0.105^{*}$ & $-0.117^{* *}$ & $-0.118^{* *}$ & -0.042 & -0.044 \\
& $(0.045)$ & $(0.046)$ & $(0.044)$ & $(0.045)$ & $(0.049)$ & $(0.049)$ \\
Mobile internet $(\mathrm{t}+1)$ & -0.024 & -0.025 & -0.031 & -0.031 & -0.056 & -0.054 \\
& $(0.029)$ & $(0.029)$ & $(0.029)$ & $(0.029)$ & $(0.047)$ & $(0.048)$ \\
Mobile internet $(\mathrm{t}+2)$ & 0.031 & 0.030 & 0.038 & 0.041 & 0.066 & 0.060 \\
& $(0.032)$ & $(0.032)$ & $(0.035)$ & $(0.035)$ & $(0.043)$ & $(0.042)$ \\
\hline Fixed effects & Country & Country & District & District & Grid cell & Grid cell \\
Demographic cntrls & No & Yes & No & Yes & No & Yes \\
Observations & 4,791 & 4,727 & 4,791 & 4,727 & 4,791 & 4,727 \\
\hline \hline
\end{tabular}

Notes: Difference-in-differences results show the effect of future access to mobile internet on a respondent identifying more nationally than ethnically. All specifications include fixed effects for survey wave and either country, district, or grid cell. Columns 5 and 6 aggregate the treatment to $0.5 \times 0.5$ degree grid cells to enable two way fixed effects. Demographic controls include individual-level measures of gender, age, completion of secondary education, and whether their residence is classified as urban or rural by Afrobarometer. Robust standard errors clustered at the locality or grid cell level are shown in parentheses. ${ }^{*} \mathrm{p}<0.05 ;{ }^{* *} \mathrm{p}<0.01 ;{ }^{* * *} \mathrm{p}<0.001$. 


\section{A.8 Balance on election proximity}

Table A9: Balance on "months from nearest election" variable

\begin{tabular}{lccccc}
\hline \hline & \multicolumn{5}{c}{ Dependent variable: } \\
\cline { 2 - 6 } & $(1)$ & $(2)$ & $(3)$ & $(4)$ & $(5)$ \\
\hline Female & -0.034 & & & \\
Age & $(0.020)$ & -0.003 & & & \\
& & $(0.004)$ & 0.166 & & \\
Education & & & $(0.145)$ & $0.510^{*}$ & \\
Urban & & & & $(0.250)$ & $0.393^{* *}$ \\
& & & & & $(0.070)$ \\
Wealth & & & & & \\
& & & & & \\
Constant & $15.545^{* * *}$ & $15.642^{* * *}$ & $15.460^{* * *}$ & $15.309^{* * *}$ & $14.931^{* * *}$ \\
& $(0.124)$ & $(0.202)$ & $(0.118)$ & $(0.139)$ & $(0.142)$ \\
\hline Observations & 59,874 & 59,602 & 59,573 & 59,881 & 59,169 \\
\hline \hline
\end{tabular}

Notes: Result of a balance test on election proximity variable, assessed by running a bivariate regression on "months from nearest election" variable using the following predictors: Female (binary), Age (binary), Education (binary, secondary school or above), Urban (binary), Wealth (index). Robust standard errors clustered at the locality level are shown in parentheses. ${ }^{*} \mathrm{p}<0.05 ;{ }^{* *} \mathrm{p}<0.01 ;{ }^{* * *} \mathrm{p}<0.001$. 


\section{A.9 Alternate outcome: "My ethnic group is treated unfairly"}

Table A10: Effect of Cell Phone Coverage on Belief Ethnic Group is Treated Unfairly (binary)

\begin{tabular}{lcccc}
\hline \hline & \multicolumn{4}{c}{ Dependent variable: } \\
\cline { 2 - 5 } & \multicolumn{4}{c}{ R's ethnic group treated unfairly by gov't (binary) } \\
& $(1)$ & $(2)$ & $(3)$ & $(4)$ \\
\hline Mobile internet coverage & $0.026^{* * *}$ & $0.019^{* * *}$ & $0.028^{* * *}$ & $0.020^{* * *}$ \\
& $(0.008)$ & $(0.007)$ & $(0.008)$ & $(0.007)$ \\
\hline Fixed effects & Country & District & Country & District \\
Demographic controls & No & No & Yes & Yes \\
Observations & 51,340 & 51,340 & 50,940 & 50,940 \\
\hline \hline
\end{tabular}

Notes: Result of the DiD analysis on alternate outcome; perceptions of ethnic discrimination. Robust standard errors clustered at the locality level are shown in parentheses. Demographic controls include individual-level measures of gender, age, completion of secondary education, and whether their residence is classified as urban or rural by Afrobarometer. ${ }^{*} \mathrm{p}<0.05 ;{ }^{* *} \mathrm{p}<0.01 ;{ }^{* * *} \mathrm{p}<0.001$.

The Afrobarometer also asks whether the respondent's ethnic group is treated unfairly by the government. We find that respondents with mobile internet coverage are approximately two percentage points more likely to believe that their ethnic group is treated unfairly. 